\title{
COMPOSITION OF CORROSION FILMS ON LITHIUM HYDRIDE SURFACES AFTER EXPOSURE TO AIR
}

J. F. McLaughlin

S. S. Cristy

\section{OAK RIDGE Y-12 PLANT}

OAK RIDGE, TENNESSEE

\section{prepared for the U.S. ATOMIC ENERGY COMMISSION}

under U.S. GOVERNMENT Contract W.7405 eng 26

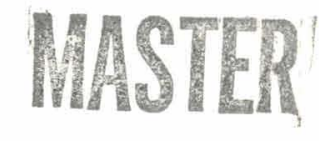




\section{DISCLAIMER}

This report was prepared as an account of work sponsored by an agency of the United States Government. Neither the United States Government nor any agency Thereof, nor any of their employees, makes any warranty, express or implied, or assumes any legal liability or responsibility for the accuracy, completeness, or usefulness of any information, apparatus, product, or process disclosed, or represents that its use would not infringe privately owned rights. Reference herein to any specific commercial product, process, or service by trade name, trademark, manufacturer, or otherwise does not necessarily constitute or imply its endorsement, recommendation, or favoring by the United States Government or any agency thereof. The views and opinions of authors expressed herein do not necessarily state or reflect those of the United States Government or any agency thereof. 


\section{DISCLAIMER}

Portions of this document may be illegible in electronic image products. Images are produced from the best available original document. 
Printed in the United States of America. Available from

National Technical Information Service

U.S. Department of Commerce

5285 Port Royal Road, Springfield, Virginia 22151

Price: Printed Copy $\$ 4.00$; Microfiche $\$ 0.95$

This report was prepared as an account of work sponsored by the United States Government. Neither the United States nor the United States Atomic Energy Commission, nor any of their employees, nor any of their contractors, subcontractors, or their employees, makes any warranty, express or implied, or assumes any legal liability or responsibility for the accuracy, completeness or usefulness of any information, apparatus, product or process disclosed, or represents that its use would not infringe privately owned rights. 
J. F. McLaughlin

S. S. Cristy

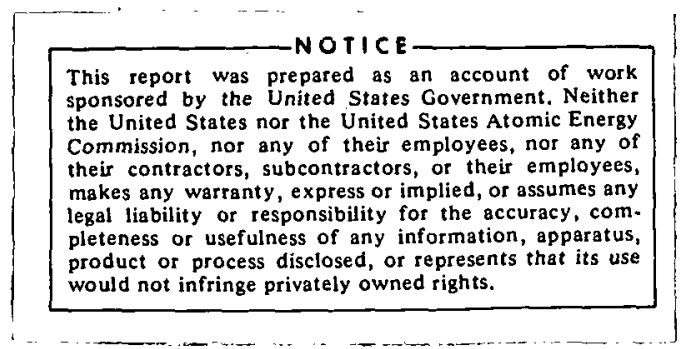

Oak Ridge $Y \cdot 12$ Plant

P.O. Box Y. Oak Ridge, Tennessee 37830

Date. Issued - March 11, 1974

Prepared for the U.S. Atomic Energy Commission

Under U.S. Government Contract W-7405-eng-26 


\begin{abstract}
An ion microprobe mass analyzer was used to investigate the reaction pathway for the formation of lithium hydroxide and lithium oxide on freshly cleaved lithium deuteride surfaces. Mass spectra were obtained from the lithium deuteride surfaces before and after exposure to room air, and the composition of the corrosion film was determined by depthprofiling methods. The corrosion film appears to be layered in the following manner: lithium hydroxide on lithium oxide on lithium deuteride.
\end{abstract}


CONTENTS

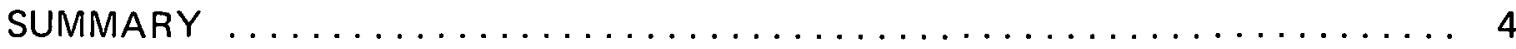

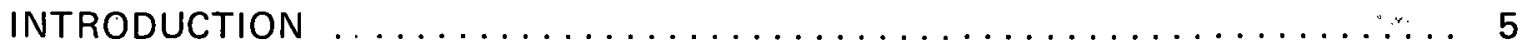

EXAMINATION OF CORROSION FILMS $\ldots \ldots \ldots \ldots \ldots \ldots \ldots \ldots \ldots \ldots$

Ion Microprobe Mass Ảnalyzer $\ldots \ldots \ldots \ldots \ldots \ldots \ldots \ldots \ldots \ldots \ldots \ldots \ldots \ldots \ldots$

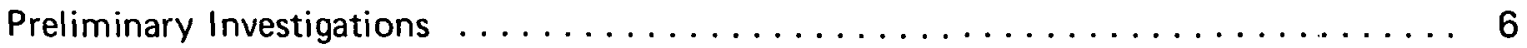

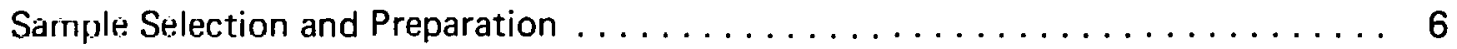

Examination of Enriched Lithium Deuteride with Nitrogen . . . . . . . . . 7

Examination of Enriched Lithium Deuteride with Negatively Charged Oxygen . . 8

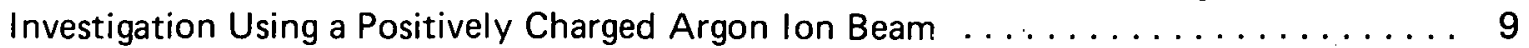

Positive Secondary Ion Mass Spectrum ...................... 9

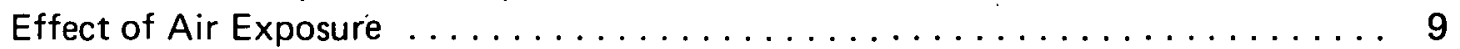

Mass Spectra of the Hydroxide, Oxide, and Carbonate . . . . . . . . . . . 11

Negative Secondary Ion Mass Spectrum $\ldots \ldots \ldots \ldots \ldots \ldots \ldots \ldots \ldots \ldots \ldots$

Effect of Air Exposure ............................ 14

Characterization of Unexposed Enriched Lithium Deuteride $\ldots \ldots \ldots \ldots \ldots \ldots$

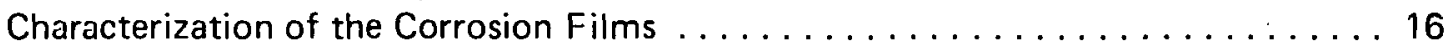

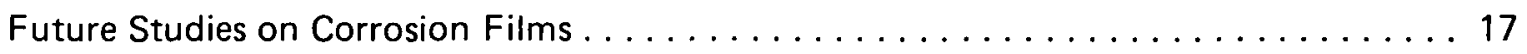

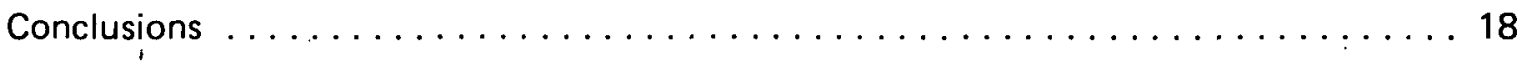

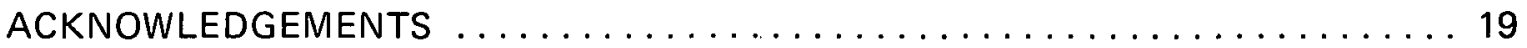

APPENDIX A.............................. 20

Specially Designed Sample Holder . . . . . . . . . . . . . . . . . . . . 20

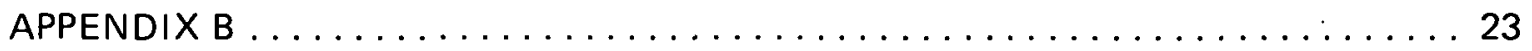

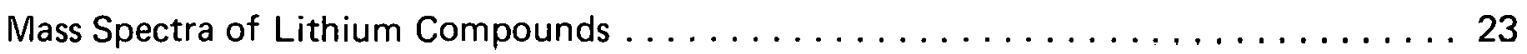

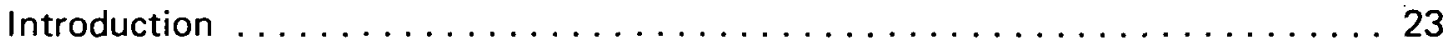

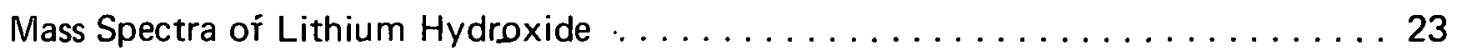

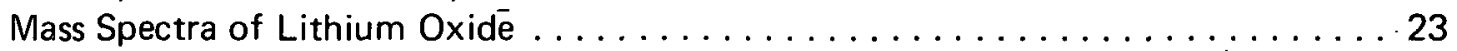

Mass Spectra of Lithium Carbonate . . . . . . . . . . . . . . 23 
The reaction mechanism in the formation of the corrosion film on lithium hydride was determined using the ion microprobe mass analyzer. Data obtained indicate the presence of distinct lithium hydroxide and lithium oxide corrosion layers on lithium deuteride after exposure to air. Transfer of unexposed samples of lithium deuteride from dry argon atmospheres to the ion microprobe sample chamber was made possible by using a special vacuum sample holder. Negative secondary-ion mass spectra of the corrosion film showed marked differences when compared to the spectrum from a freshly cleaved crystal that had not been exposed to air. Data obtained in this investigation show that layering does occur and that the corrosion film consists of a layer of lithium hydroxide on a layer of lithium oxide on the lithium deuteride crystals. 


\section{INTRODUCTION}

The purpose of this study was to determine the reaction pathway for the formation of lithium hydroxide and lithium oxide on lithium hydride surfaces. When lithium hydride or lithium deuteride is exposed to air, a number of reactions take place that result in the formation of lithium hydroxide, lithium oxide, hydrogen, hydrogen deuteride, and, in some cases, lithium carbonate.

Two possible reaction sequences are proposed for the reaction of lithium hydride with the water in air:

$$
\begin{aligned}
& \mathrm{LiH}+\mathrm{H}_{2} \mathrm{O} \longrightarrow \mathrm{LiOH}+\mathrm{H}_{2} \text {, then } \\
& \mathrm{LiOH}+\mathrm{LiH} \longrightarrow \mathrm{Li}_{2} \mathrm{O}+\mathrm{H}_{2} \text {; or } \\
& \mathrm{LiH}+\mathrm{H}_{2} \mathrm{O} \longrightarrow \mathrm{LiOH}+\mathrm{H}_{2} \text {, then } \\
& \mathrm{LiOH}+\mathrm{LiOH} \longrightarrow \mathrm{Li}_{2} \mathrm{O}+\mathrm{H}_{2} \mathrm{O} .
\end{aligned}
$$

If the pathway is Sequence A, layering might take place with lithium hydroxide being first formed on the lithium hydride. Then, as the lithium hydroxide reacts with the lithium hydride, a layer of lithium oxide is built up between the lithium hydroxide and lithium hydride. If the pathway is Sequence $B$, the lithium oxide will be evenly distributed thoughout the lithium hydroxide layer.

The ion microprobe mass analyzer was used to study the processes involved when either lithium hydride or lithium deuteride was exposed to moisture. Removal of successive layers of material from the surface by sputtering indicates that layering takes place and that the reaction pathway is that described in Sequence $A$.

This report presents the results' of the ion microprobe characterization of the lithium hydride surfaces, both before and after exposure to air, as performed at the Oak Ridge Y-12 Plant. (a)

(a) Operated by the Union Carbide Corporation's Nuclear Division for the US Atomic Energy Commission. 


\section{EXAMINATION OF CORROSION FILMS}

\section{ION MICROPROBE MASS ANALYZER}

The ion microprobe mass analyzer (IMMA) used in this work was basically designed by Liebl. (b) This instrument provides in situ mass analysis of a microvolume at the surface of a solid sample. Analyses are performed by bombarding the sample surface with a high-energy $(0-20 \mathrm{kv})$ beam of monoisotopic ions (usually oxygen or nitrogen) which causes the atoms to leave the surface because of sputtering. Some fraction of the sputtered atoms is ionized, and these ions are analyzed according to their mass-to-charge ratio $(\mathrm{m} / \mathrm{e})$ in a mass spectrometer. The ion microprobe permits a detailed analysis of a sample, with depth, as the successive atom layers are sputtered away. The minimum beam diameter is about two micrometers. Because the IMMA has a very low penetrating power, depth resolution is only a few atom layers near the sample surface. Data obtained can be recorded oscillographically, by pulse counting, or by a graphical display of the mass spectrum.

\section{PRELIMINARY INVESTIGATIONS}

\section{Sample Selection and Preparation}

In order to facilitate identification of the substrate/corrosion film interface, single crystals of enriched lithium deuteride were used throughout the investigation. Reasons for the selection of this material are:

1. Use of a nearly monoisotopic lithium content reduced the composition of mass peaks in the mass spectrum, such as $\mathrm{m} / \mathrm{e}=23$, which can be due to at least three ions $\left({ }^{6} \mathrm{LiOH}^{+}\right.$, ${ }^{7} \mathrm{LiO}^{+}$, and any ${ }^{23} \mathrm{Na}^{+}$impurity).

2. Deuteride was chosen because any hydrogen found in the resulting mass spectra would have to originate as a result of the reaction of the crystal with water.

3. Chemical purity $\left(6_{\mathrm{Li}}\right.$ assay) and the deuterium content were accurately known.

4. This material was readily available and representative of that routinely used in the $Y-12$ Plant.

A chemical analysis of a sample of the material used is presented in Table 1.

The crystals were prepared for examination inside an argon-filled dry box with a moisture content of 1 to 2 parts per million (ppm). A small piece of lithium deuteride was cleaved from a larger crystal and pressed into indium metal in a recess in a standard one-inch-diameter sample holder. The mounted crystal was then transferred to a vacuum evaporator with a minimum exposure to air. A layer of gold was vacuum evaporated onto

(b) Liebl, H.; "Ion Microprobe Mass Analyzer", J Appl Physics, 38, p 5277 (1967). 
the surface to seal the surface from further exposure. The gold layer also served as a conduction path to remove any charge built up on the surface while sputtering. Removal of any charging from the sample surface insures that the accelerating electrical field above the sample (which accelerates the ions into the secondary mass spectrometer) is free from distortion. This procedure is unsatisfactory, since the lithium deuteride crystal is heated by radiant heat from the tungsten filament during vacuum evaporation of the gold. When the lithium deuteride crystal and the protective gold film cool in the vacuum after the evaporation, the gold film buckles on the lithium deuteride crystal surface due to the difference in their coefficients of thermal expansion. To circumvent the charging problem, a 1/4-inch square of electroformed screen is placed on the surface of the crystal, as indicated in Figure 1 which is a diagram of a sample mounted in this manner. This arrangement provides electrical contact from the screen to the indium.

Mass spectra were obtained from a sample of lithium deuteride mounted, as described, using a positively charged oxygen ion beam. Data obtained from this sample were in good agreement with the positive lithium- 6 ion content. The amount of positive lithium- 6 ion was calculated to be 94.9 percent, compared with a value of 95 percent from the laboratory analysis. However, the deuterium content was consistently very low, never exceeding 10 percent even after 16 hours of sputtering. It appeared that the screen covering the lithium deuteride crystal contained relatively large amounts of hydrogen so that hydrogen migrating

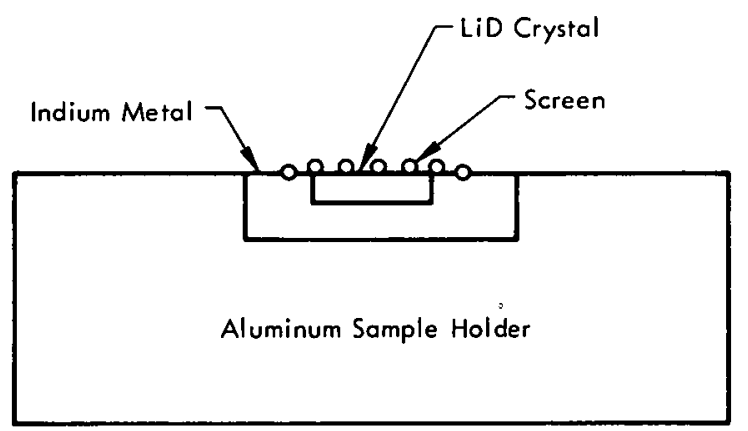

Figure 1. METHOD OF MOUNTING A SCREEN ON THE SURFACE OF A LITHIUM DEUTERIDE CRYSTAL TO REMOVE THE ELECTRICAL CHARGE DURING SPUTTERING. from the screen to the lithium deuteride caused the observed low deuterium-tohydrogen ratio.

\section{Examination of Enriched Lithium Deuter- ine with Nitrogen}

Because the examination of enriched lithium deuteride just described, using a positively charged oxygen ion beam, failed to show any. reasonable hydrogen-to-deuteri-, um ratios, a positively charged nitrogen ion beam was used for higher current densities and more rapid sputtering. 
A freshly cleaved crystal of enriched lithium deuteride was mounted as portrayed in Figure 1 and placed in the ion microprobe. Mass spectra from the surface of the crystal revealed a corrosion film caused by the short exposure (less than 30 seconds) to the room air during transfer from the argon atmosphere into the IMMA sample chamber.

In this examination, the ion microprobe monitored the positive deuterium ion $(\mathrm{m} / \mathrm{e}=2)$ concentration by mass profiling. Mass profiling is a technique in which the secondary-ion mass spectrometer is set to monitor a specific mass-to-charge $(\mathrm{m} / \mathrm{e})$ ratio as a function of the sputtering time (depth). The secondary ion intensity is measured by pulse-counting techniques and printed out on a teletypewriter. The data can then be plotted as a function of time by showing any variation of the selected ion intensity as a function of the sputtering depth.

The deuterium ( $\mathrm{m} / \mathrm{e}=2$ ) ion intensity was monitored as a function of the sputtering time. The deuterium positive ion intensity rose initially at a fairly rapid rate, then gradually climbed to a plateau after $21 / 2$ hours of sputtering. The deuterium and hydrogen concentrations were determined after three hours of sputtering, and the deuterium content was found to be 90.5 percent. This run was the first time that the deuterium content (as determined in the (MMA) approached the laboratory analysis value of 98.3 percent. It should be noted that, even though the crystal was mounted with a screen to help provide a conduction path, charging did occur to a limited extent.

\section{Examination of Enriched Lithium Deuteride with Negatively. Charged Oxygen}

A freshly cleaved enriched lithium deuteride crystal was placed in the IMMA, using the vacuum sample holder, $(\mathrm{c})$ and was examined with a negatively charged oxygen ion beam. The mass spectra obtained indicated that the crystal had a corrosion film on the surface. Even after prolonged sputtering, the mass spectrum showed evidence of a corrosion film. These data suggested that there was some source of water within the instrument that was of sufficient quantity to continually react with the enriched lithium deuteride as the ion beam sputtered into the crystal. A residual gas analyzer (quadrupole) was attached to the ion microprobe to obtain an analysis of the gas in the instrument. It was observed that, when the oxygen beam was turned on, the amount of water in the system increased significantly. A laboratory analysis of the oxygen gas being used in the ion source of the IMMA showed that the oxygen contained $55 \mathrm{ppm}$ water. Another bottle of oxygen was tried, but it too produced water in the residual gas analyzer spectrum, although not as much as with the original oxygen sypply. Because of this problem, it was decided to try argon as the primary beam.

(c) Construction and operational details for the vacuum sample holder are provided in Appendix A. 


\section{INVESTIGATION USING A POSITIVELY CHARGED ARGON ION BEAM}

\section{Positive Secondary Ion Mass Spectrum}

Three, small, freshly cleaved enriched lithium deuteride crystals were mounted in indium metal and transferred to the ion microprobe, in the vacuum sample holder, where they were examined using a positively charged argon ion beam. These crystals were mounted without pressing a molybdenum screen on the surface. Some charging did take place, but was minimal when the primary beam was kept near the edge of the enriched lithium deuteride crystal. Positive secondary ion mass spectra were obtained, and the deuterium content exceeded the hydrogen content. There was evidence of a very thin corrosion film on the surface; but, after one minute, the argon beam had sputtered through the film into the enriched lithium deuteride crystal. The deuterium and hydrogen contents were monitored by mass profiling. The data obtained are plotted as a function of the sputtering time in Figure 2. These data show that the deuterium concentration rises very rapidly as the ion beam sputters through the thin surface film. This action is accompanied by a corresponding rapid decrease in the hydrogen concentration. At the end of one hour of sputtering time, both the deuterium and hydrogen contents were measured using pulse-counting techniques. The observed deuterium contenl was found to be 96.3

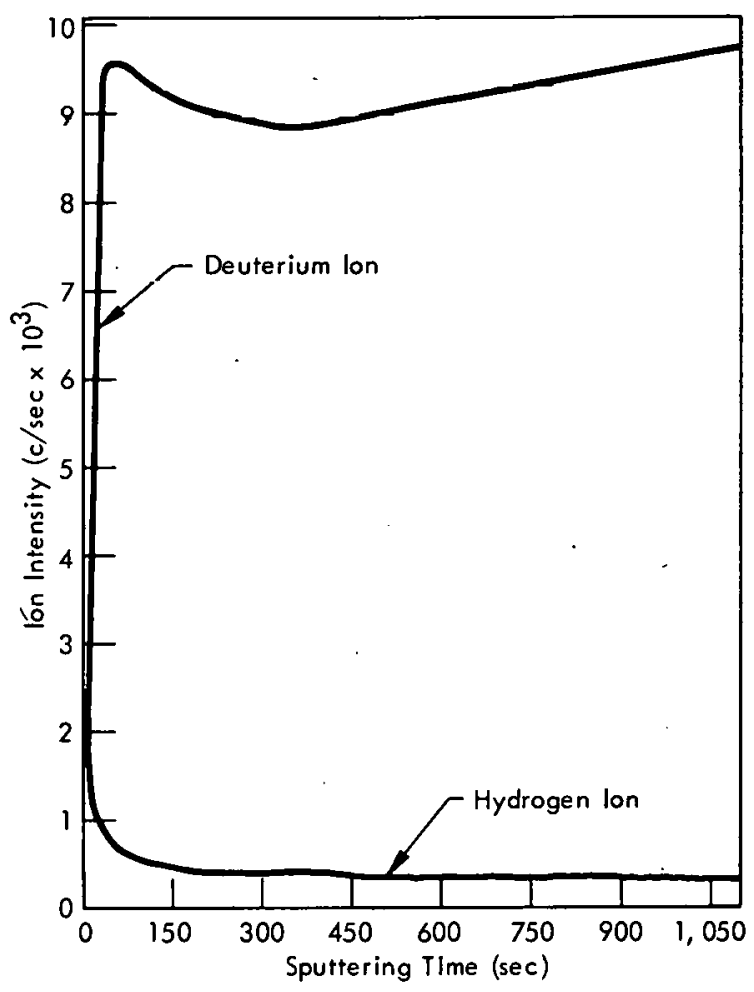

Figure 2. DEPTH PROFILES FOR THE POSITIVE HYDROGEN AND DEUTERIUM IONS IN A LITHIUM Deuteride CRYStal. (Argon Positive Ion Primary Beaml percent, which is in acceptable agreement with the 98.3 percent reported in the laboratory analysis. A positive secondary ion mass spectrum, seen in Figure 3, was obtained from this sample. As seen, the mass spectrum is relatively simple, with only a few peaks present. Only that portion of the mass spectrum from $m / e=1$ to $m / e=40$ is shown, since any diagnostic peaks would appear within this mass-to-charge range.

\section{Effect of Air Exposure}

The same sample was exposed to room air at $74^{\circ} \mathrm{F}$ and 33 percent relative humidity for one minute. After this exposure, positive secondary mass scans were obtained, one of which can be seen in Figure 4. A comparison of the mass spectrum in Figure 3 with that in Figure 4 illustrates the marked differences observed. As in the case of the unexposed enriched lithium dcutcridc mass spectrum, only that portion of the mass spectrum trom $\mathrm{m} / \mathrm{e}=1$ to $\mathrm{m} / \mathrm{e}=\mathbf{4 0}$ is shown, because the diagnostic peaks fall within this range. The complexity of 
these mass spectra did not permit a straightforward interpretation of the corrosion mechanism.

After obtaining the data from this sample, the primary beam was rastered over an area of the exposed surface to sputter down into the corrosion film. After one and one-half hours of sputtering, the mass spectrum (Figure 5) was obtained. This mass spectrum represents some intermediate depth between the surface of the corrosion layer and the enriched lithium deuteride substrate.

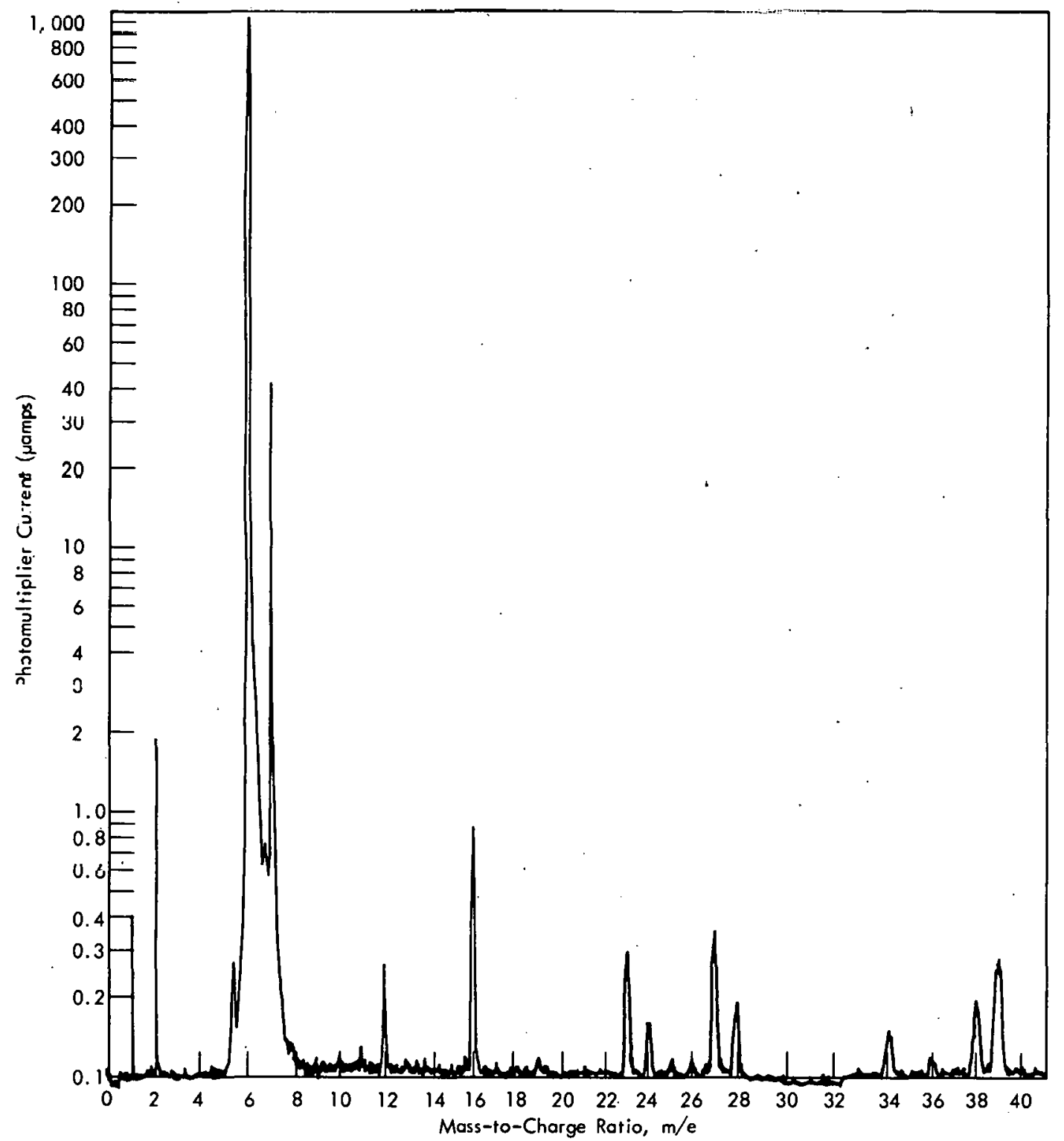

Figure 3. POSITIVE SECONDARY MASS SPECTRUM FOR ENRICHED LITHIUM DEUTERIDE. (Argon Positive Ion Primary Beam) 


\section{Mass Spectra of the Hydroxide, Oxide, and Carbonate}

Since the results of the preceding experiment proved to be complex, the most direct approach to identification of the corrosion products appeared to be a comparison of the observed mass spectra from the corrosion film with known mass spectra obtained from pure materials. Samples of the suspected corrosion products $\left(\mathrm{LiOH}, \mathrm{Li}_{2} \mathrm{O}\right.$, and $\left.\mathrm{Li}_{2} \mathrm{CO}_{3}\right)$ were prepared. Each of these materials were prepared from commercially available chemicals containing the naturally occuring isotopic composition of lithium. The carbonate was a certified reagent powder. This material was pressed into the cavity in an aluminum sample block in an argon atmosphere. The sample was placed in the vacuum sample holder, evacuated, and transferred to the ion microprobe in the same manner as the enriched

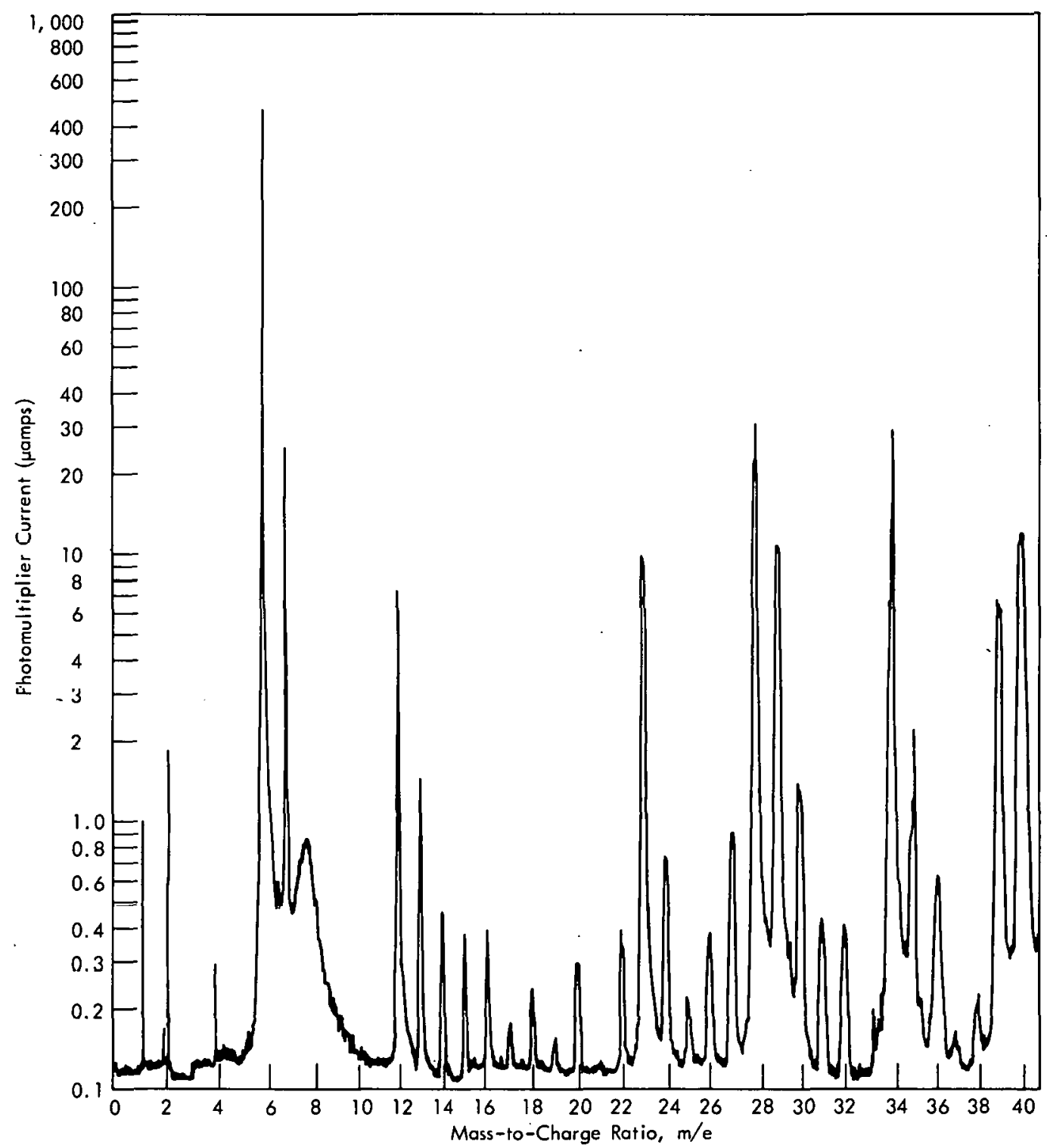

Figure 4. POSITIVE SECONDARY MASS SPECTRUM FOR ENRICHED LITHIUM DEUTERIDE AFTER EXPOSURE TO ROOM AIR. 
lithium deuteride was handled. Both positive and negative secondary mass spectra were obtained using a positively charged argon primary beam. These data are included in Appendix B.

The lithium hydroxide sample was prepared by the slow dehydration of purified hydrated lithium hydroxide polycrystalline material. Both positive and negative mass spectra were obtained along with pulse-counting data for each peak in the mass spectra. These data are also included in Appendix B.

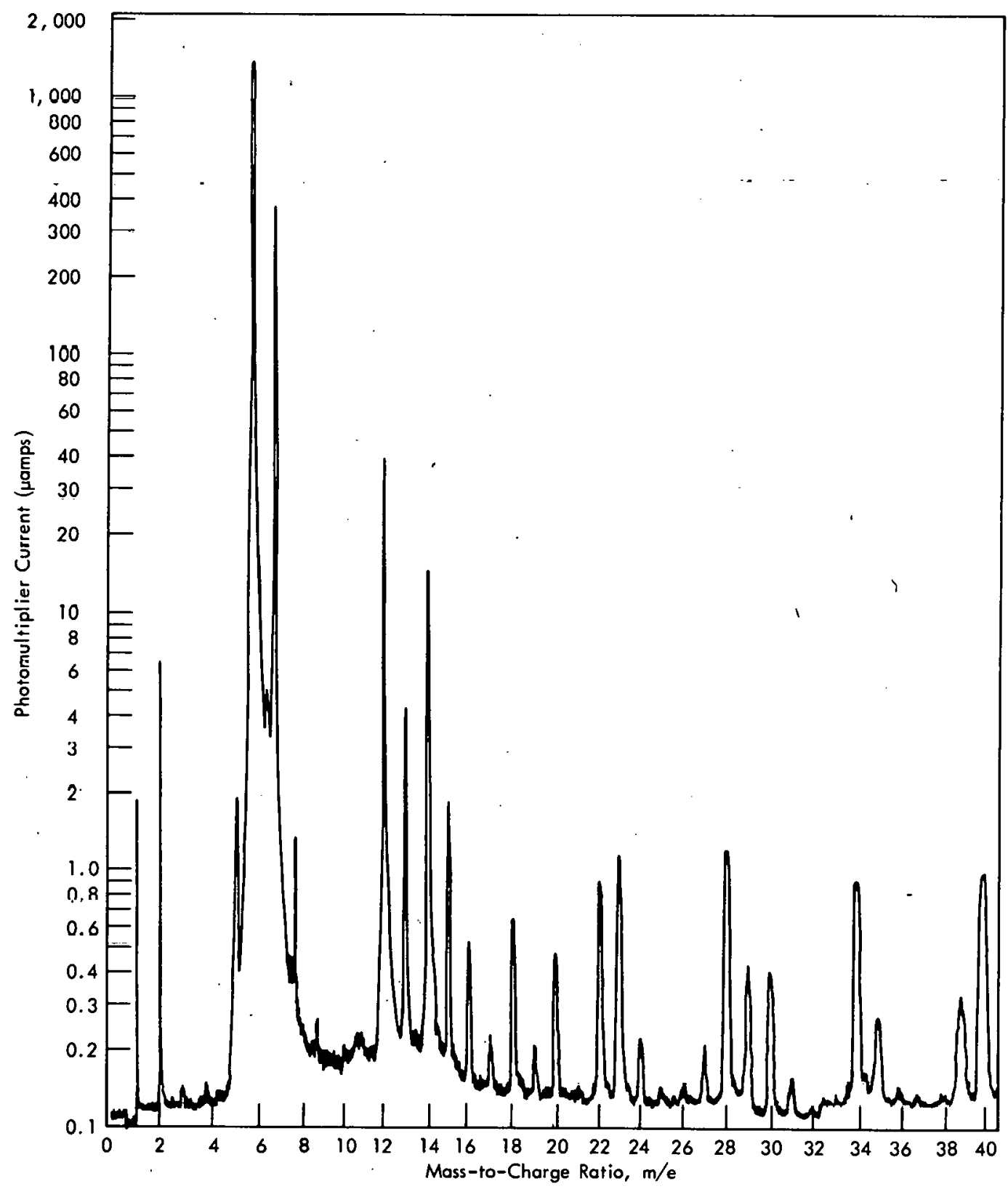

Figure 5. POSITIVE SECONDARY MASS SPECTRUM OF AIR-EXPOSED ENRICHED LITHIUM DEUTERIDE AFTER SPUTTERING FOR 1 1/2 HOURS. 
Lithium oxide was prepared from the same starting material as the lithium hydroxide sample by complete dehydration of hydrated lithium hydroxide according to the reaction:

$$
2 \mathrm{LiOH} \cdot \mathrm{H}_{2} \mathrm{O}(\mathrm{s})+\text { heat } \longrightarrow \mathrm{Li}_{2} \mathrm{O}(\mathrm{s})+3 \mathrm{H}_{2} \mathrm{O}(\mathrm{g})
$$

This sample was handled in the same manner as were the other two polycrystalline samples. The positive and negative mass spectra obtained along with the pulse cointing data are presented in Appendix B.

An examination of the mass spectra of these reaction products showed that the negative mass spectra appeared to be the most diagnostic since there were definite differences which were lacking in the positive spectra.

\section{Negative Secondary Ion Mass Spectrum}

Freshly cleaved enriched lithium deuteride crystals were examined in the ion microprobe using a positively charged argon ion beam and recording the negative secondary mass spectra. The mass spectrum obtained from this run is given in Figure 6 . The negative mass spectrum is extremely simple compared to the positive mass spectrum (Figure 3 ). The only peaks in this spectrum are due to hydrogen $(\mathrm{m} / \mathrm{e}=1)$, deuterium $(\mathrm{m} / \mathrm{e}=2)$ lithium $(\mathrm{m} / \mathrm{e}=6$, 7 , and 12), oxygen (m/e $=16)$, and a trace of the hydroxyl ion (m/e $=17)$. Because of the differences in the spectra at $\mathrm{m} / \mathrm{e}=1,2,12,16$, and 17 , the negative mass spectrum was found to be the most diagnostic.

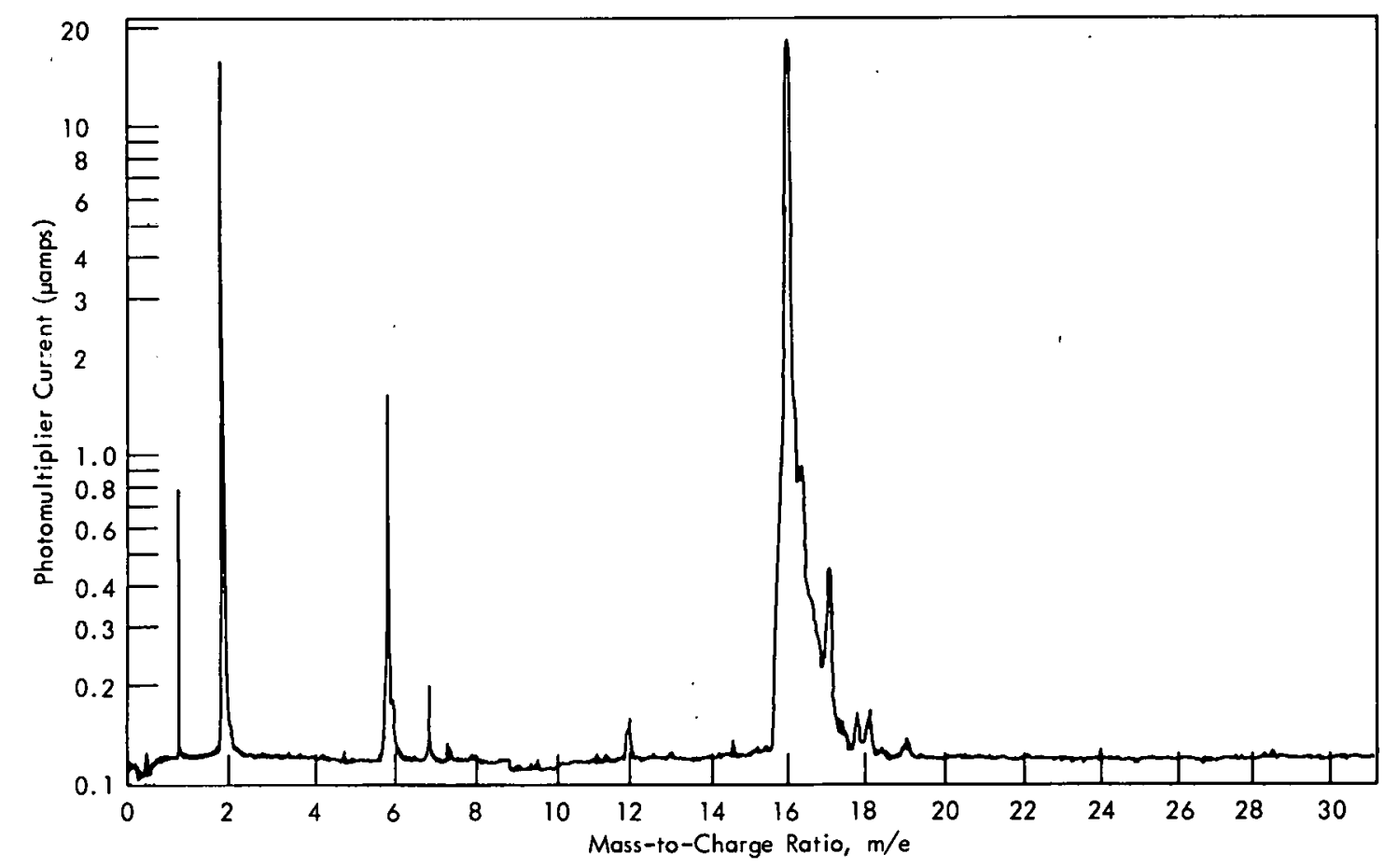

Figure 6. NEGATIVE SECONDARY MASS SPECTRUM OF ENRICHED LITHIUM DEUTERIDE FROM AN ARGON POSITIVE ION PRIMARY BEAM. 


\section{Effect of Air Exposure}

The freshly cleaved enriched lithium deuteride sample was next exposed to room air at $72^{\circ} \mathrm{F}$ and 65 percent relative humidity for 35 seconds. Negative mass spectra were obtained using a positively charged argon ion beam. A typical mass spectrum from the air-exposed surface is presented in Figure 7. This mass spectrum is markedly different from that obtained from the unexposed enriched lithium deuteride crystal surface (compare Figure 7 with Figure 6). The most diagnostic mass peaks are at mass-to-charge ratios of $1\left(\mathrm{H}^{-}\right), 2\left(\mathrm{D}^{-}\right), 16\left(\mathrm{O}^{-}\right)$, and $17\left(\mathrm{OH}^{-}\right)$. The $\mathrm{m} / \mathrm{e}=1$ and $\mathrm{m} / \mathrm{e}=2$ peaks can be used to define the corrosion film/lithium deuteride interface, while the $\mathrm{m} / \mathrm{e}=16$ and $\mathrm{m} / \mathrm{e}=17$ peaks can be used to identify the presence of oxide and hydroxide, respectively. Peaks seen at other mass-to-charge ratios are due to impurities. The reason these peaks were not seen in the mass spectrum from the unexposed crystal is that the presence of the surface film apparently enhances the ionization of the sputtered atoms from the surface. The ion beam was rastered over an area of 60 by 75 micrometers and mass scans were obtained at ten-minute intervals. Significant changes were observed in these mass spectra, notably in the intensities of the peaks at $\mathrm{m} / \mathrm{e}=1,2,16$, and 17 as the ion beam sputtered through the corrosion film.

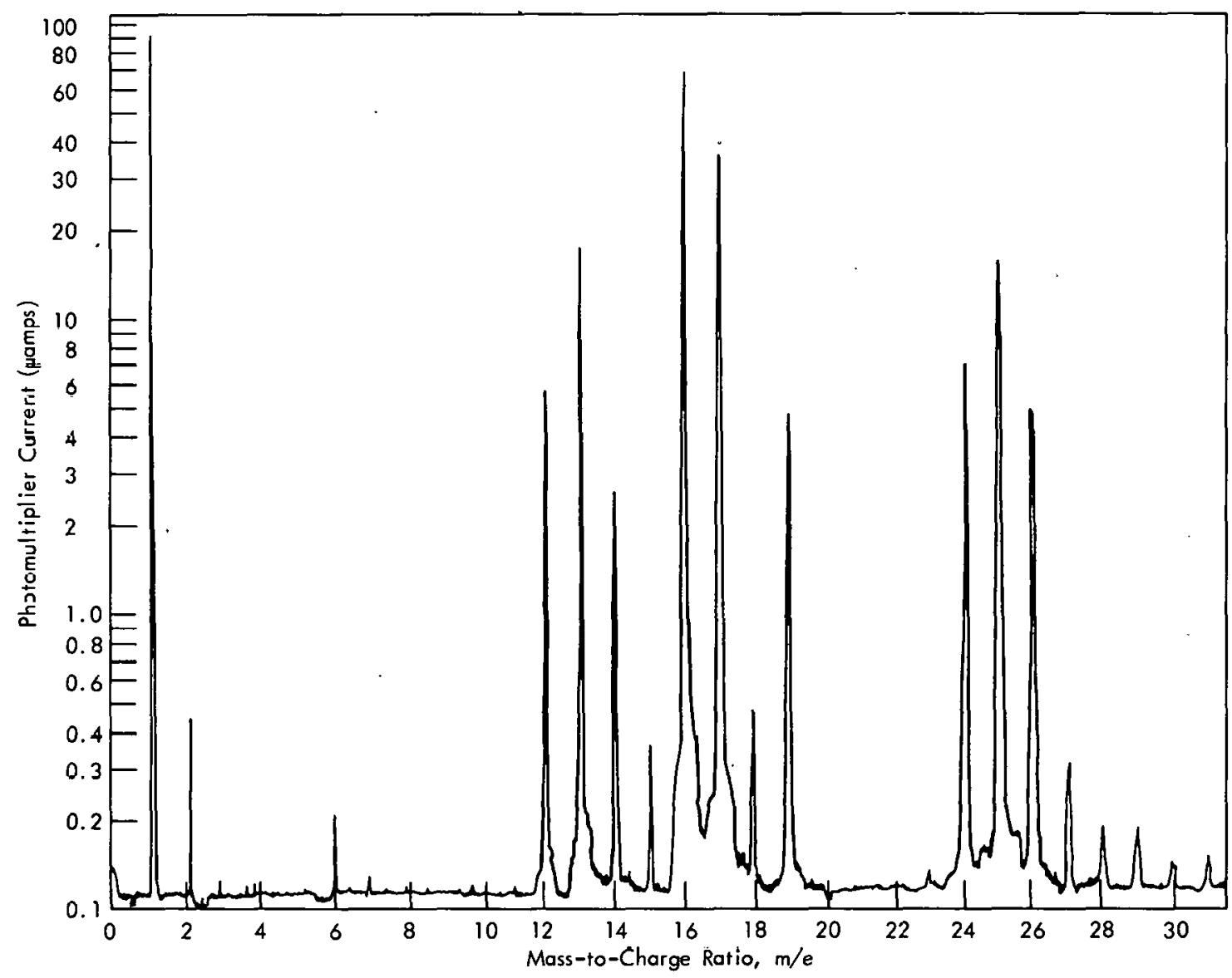

Figure 7. NEGATIVE SECONDARY MASS SPECTRUM OF ENRICHED LITHIUM DEUTERIDE AFTER EXPOSURE TO ROOM AIR AT $72^{\circ} F$ AND 65 PERCENT RELATIVE HUMIDITY FOR 35 SECONDS. 


\section{Characterization of Unexposed Enriched Lithium Deuteride}

A crystal of enriched lithium deuteride was cleaved inside an argon-filled dry box that contained $2.5 \mathrm{ppm}$ moisture. The freshly cleaved crystal was mounted in the vacuum sample holder (Appendix A) and the holder was evacuated. Total exposure time of the freshly cleaved crystal face to the dry box atmosphere was 12 minutes. The sample was transferred to the IMMA and then characterized by the mass profiling technique. The secondary mass spectrometer was set to monitor specific mass-to-charge ratios as the primary beam sputtered through the corrosion film. The ion intensity was recorded by pulse-counting techniques. Data were collected in this manner for mass-to-charge ratios of $1\left(\mathrm{H}^{-}\right), 2\left(\mathrm{D}^{-}\right)$, $16\left(\mathrm{O}^{-}\right)$, and $17\left(\mathrm{OH}^{-}\right)$. The results are reported in Figure 8. In order to make the changes in intensity as vivid as possible, the data were normalized by subtracting the minimum intensity from each data point, dividing by the maximum intensity minus the minimum intensity, and multiplying by 100 , ie:

$$
\frac{I-I_{\min }}{I_{\max }-I_{\min }} \times 100 .
$$

Thus, plotting on a scale from 0 to 100 , the minimum point is equal to zero; the maximum point is equal to 100 . As can be seen in Figure 8 , there is no evidence of any distinct layering occurring on the surface. The zone marked "surface layer" is thought to be due to

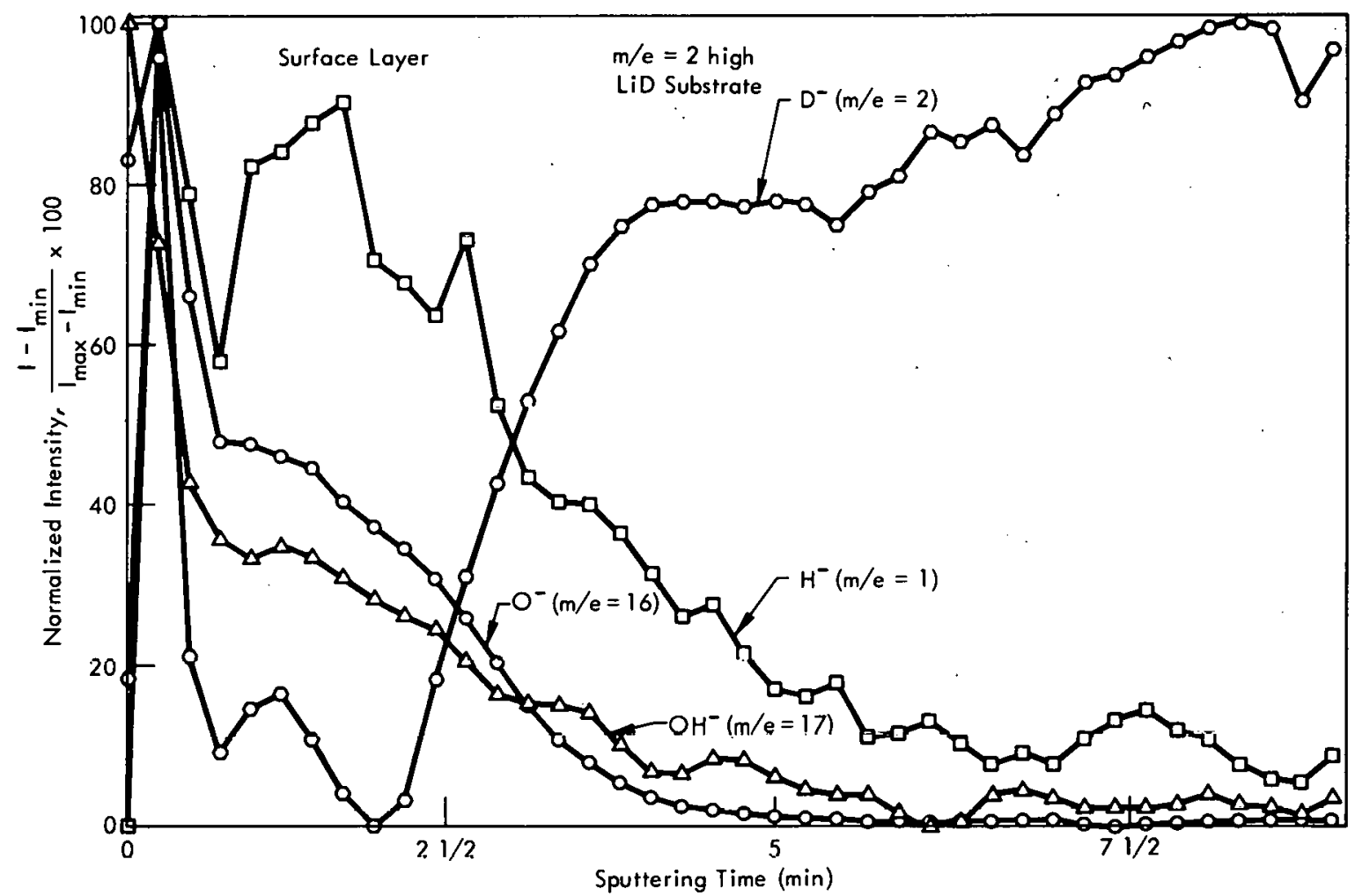

Figure 8. DEPTH PROFILES OF SELECTED MASS NUMBERS AS A FUNCTION OF THE SPUTTERING TIME. (Freshly Cleaved LiD Crystal Exposed to $2.6 \mathrm{ppm} \mathrm{H}_{2} \mathrm{O}$ in Argon for 12 Minutes) 
the sputtering of the nuclei of the corrosion film randomly spaced over the rastered surface that have not grown into a continuous film. Due to the method of normalization, the intensity variations in $\mathrm{m} / \mathrm{e}=2\left(\mathrm{D}^{-}\right)$in Figure 8 are exaggerated. The intensity on the surface and at the minimum is still a significant fraction of the maximum intensity. This relationship can be seen in Table 2, which is a listing of the maximum and minimum counting rates for each of the mass peaks shown in the mass profiles.

Table 2

PULSE-COUNTING DATA FOR MAXIMUM AND MINIMUM POINTS ON MASS PROFILING CURVES

\begin{tabular}{|c|c|c|c|c|c|c|}
\hline \multirow[b]{2}{*}{$\mathrm{m} / \mathrm{e}$} & \multicolumn{2}{|c|}{ Figure $8(1,2)$} & \multicolumn{2}{|c|}{ Figure $9(1,3)$} & \multicolumn{2}{|c|}{ Figure $10(1,4)$} \\
\hline & Point & $\begin{array}{l}\text { Pulse Cuunts } \\
\text { (cps) }\end{array}$ & Point & $\begin{array}{l}\text { Pulse Cuunls } \\
\text { (cps) }\end{array}$ & Point & $\begin{array}{l}\text { Pulsé Cuints } \\
\text { (cps) }\end{array}$ \\
\hline 1 & $\max$ & 100,016 & $\max$ & $3,110,720$ & $\max$ & 111,677 \\
\hline 1 & $\min$ & 71,186 & $\min$ & 92,572 & $\min$ & 65,853 \\
\hline 2 & $\max$ & 481,022 & $\max$ & 10,325 & $\max$ & 207,261 \\
\hline 2 & $\min$ & 264,348 & $\min$ & 67 & $\min$ & 3,407 \\
\hline 16 & $\max$ & $2,472.042$ & $\max$ & 321.983 & $\max$ & 4.859 .550 \\
\hline 16 & $\min$ & 103,923 & $\min$ & 125,916 & $\min$ & $2,781,456$ \\
\hline 17 & $\max$ & 52,280 & $\max$ & 358,412 & $\max$ & $1,001,935$ \\
\hline 17 & $\min$ & 18,250 & $\min$ & 25,842 & $\min$ & 96,505 \\
\hline
\end{tabular}

(1) In order to show the layering, these figures do not cover the sputtering times required to allow $\mathrm{m} / \mathrm{e}=1$ and 2 to reach those intensities representative of the bulk material. In the case of Figure 9, the hydrogen background in the instrument was exceptionally high.

(2) Exposed for $12 \mathrm{~min}, 2.5 \mathrm{ppm} \mathrm{H}_{2} \mathrm{O}$ in argon.

(3) Exposed for $35 \mathrm{sec}, 65 \%$ relative humidity, $72^{\circ} \mathrm{F}$, in air.

(4) Exposed for $20 \mathrm{sec}, 77 \%$ relative humidity, $72^{\circ} \mathrm{F}$, in air.

\section{Characterization of the Corrosion Films}

Since this study of the mass spectra obtained at selected intervals while sputtering through the corrosion film showed the intensities of the mass peaks of $\mathrm{H}^{-}, \mathrm{D}-\mathrm{O}^{-}$, and $\mathrm{OH}^{-}$to change, the mass profiling method of analysis was used to study the distribution of these ions in the corrosion film. A freshly cleaved crystal was characterized in the IMMA to make sure no corrosion film was present, and then was exposed to room air at 65 percent relative humidity and $72^{\circ} \mathrm{F}$ for 35 seconds. The resulting corrosion film was then examined by mass profiling. Data from this test are summarized in Figure 9. In this figure, the normalized intensity is the ordinate, while the abscissa indicates both the sputtering time in seconds and the location and composition of corrosion layers and the enriched lithium deuteride substrate. The curve for $\mathrm{m} / \mathrm{e}=16\left(\mathrm{O}^{-}\right)$contains two broad maxima (labeled $A$ and $B$ in Figure 9), the first (A) arising from the lithium hydroxide layer and the second (B) from the lithium, oxide layer. The high amount of hydrogen $(\mathrm{m} / \mathrm{e}=1)$ at the surface of the sample could be due to some hydrated lithium hydroxide. The definition of the lithium hydroxide layer is clearly shown by the $\mathrm{m} / \mathrm{e}=17\left(\mathrm{OH}^{-}\right)$maximum, and the enriched lithium deuteride substrate is defined by the high $\mathrm{m} / \mathrm{e}=2\left(D^{-}\right)$intensity. I'he experimental evidence presented here indicates that layering does occur and identifies the principal anion present in each of the layers. 


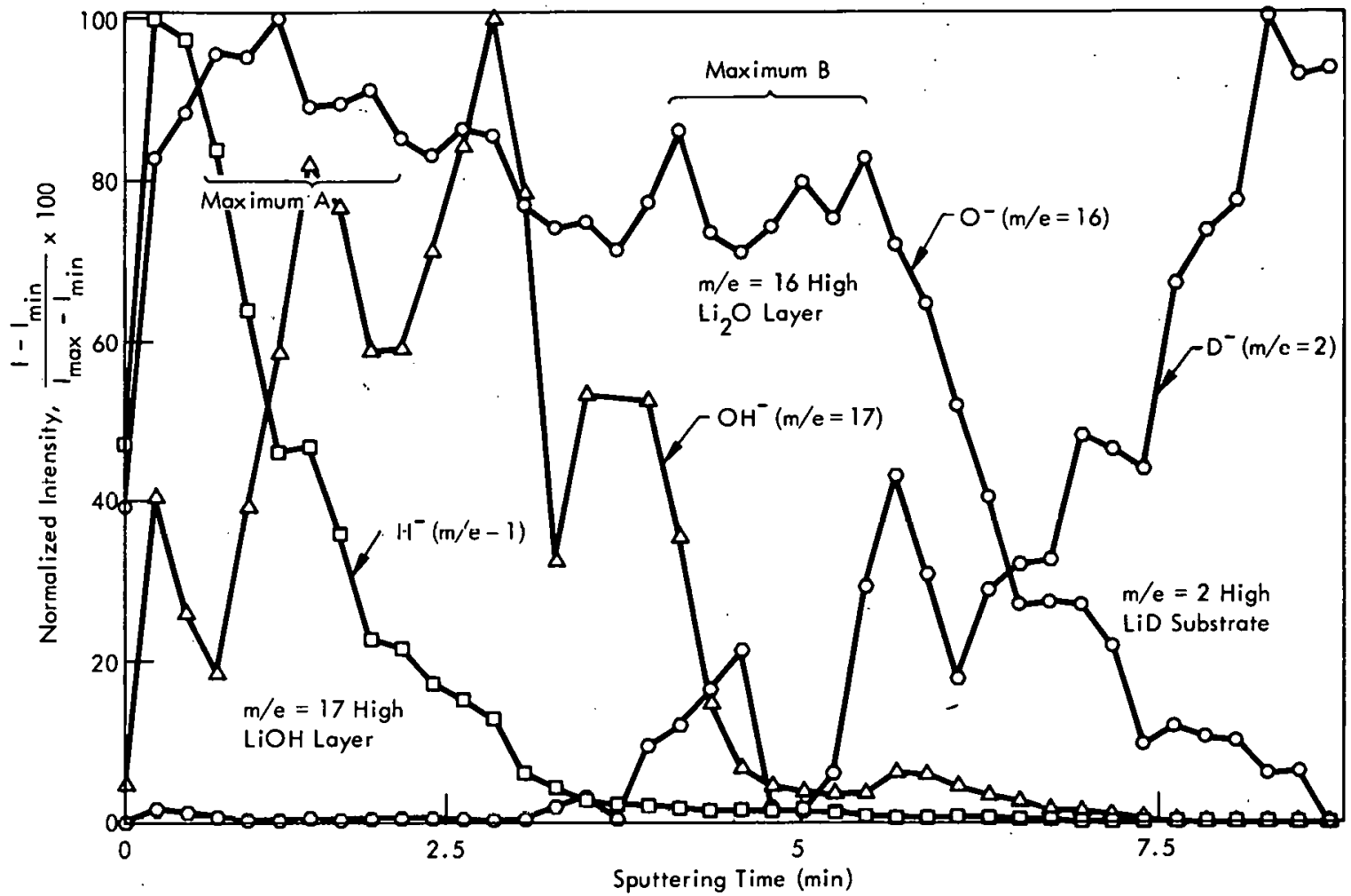

Figure 9. DEPTH PROFILES OF SELECTED MASS NUMBERS AS A FUNCTION OF THE SPUTTERING TIME. (LID Crystal Exposed to $65 \%$ Relative Humidity Air at $72^{\circ} \mathrm{F}$ for 35 Seconds)

The thickness of the layers in the corrosion film cannot be expressed in any dimensions other than sputtering time, since no samples of known thickness were available to correlate sputtering time with film thickness. The data in Figure 9 show that the time required to sputter through the lithium hydroxide layer (195 seconds) was slightly less than the time required to sputter through the lithium oxide layer (202 seconds).

Another enriched lithium dcuteride erystal was prepared and examined. The mass spectra from the surface of this crystal were the same as those given in Figure 6 . This sample was then exposed to room air at 77 percent relative humidity and $720 \mathrm{~F}$ for 20 seconds. The corrosion film was then characterized. As before, layering was evident, and the same mass-to-charge peaks were monitored as a function of the sputtering time. These data are reported in Figure 10. The time required to sputter through the lithium hydroxide layer (260 seconds) was greater than the time required to sputter through the lithium oxide (228 seconds). Reasons for the difference in sputtering time for this crystal and the previous crystals could be due to the difference in thicknesses of the corrosion film formed due to different exposure times, different relative humidities, and possibly different barometric pressures at the time of exposure.

\section{FUTURE STUDIES ON CORROSION FILMS}

The accomplishments attained to date in the study of the corrosion of lithium deuteride in air have prompted a consideration of a number of additional experiments on this problem. 


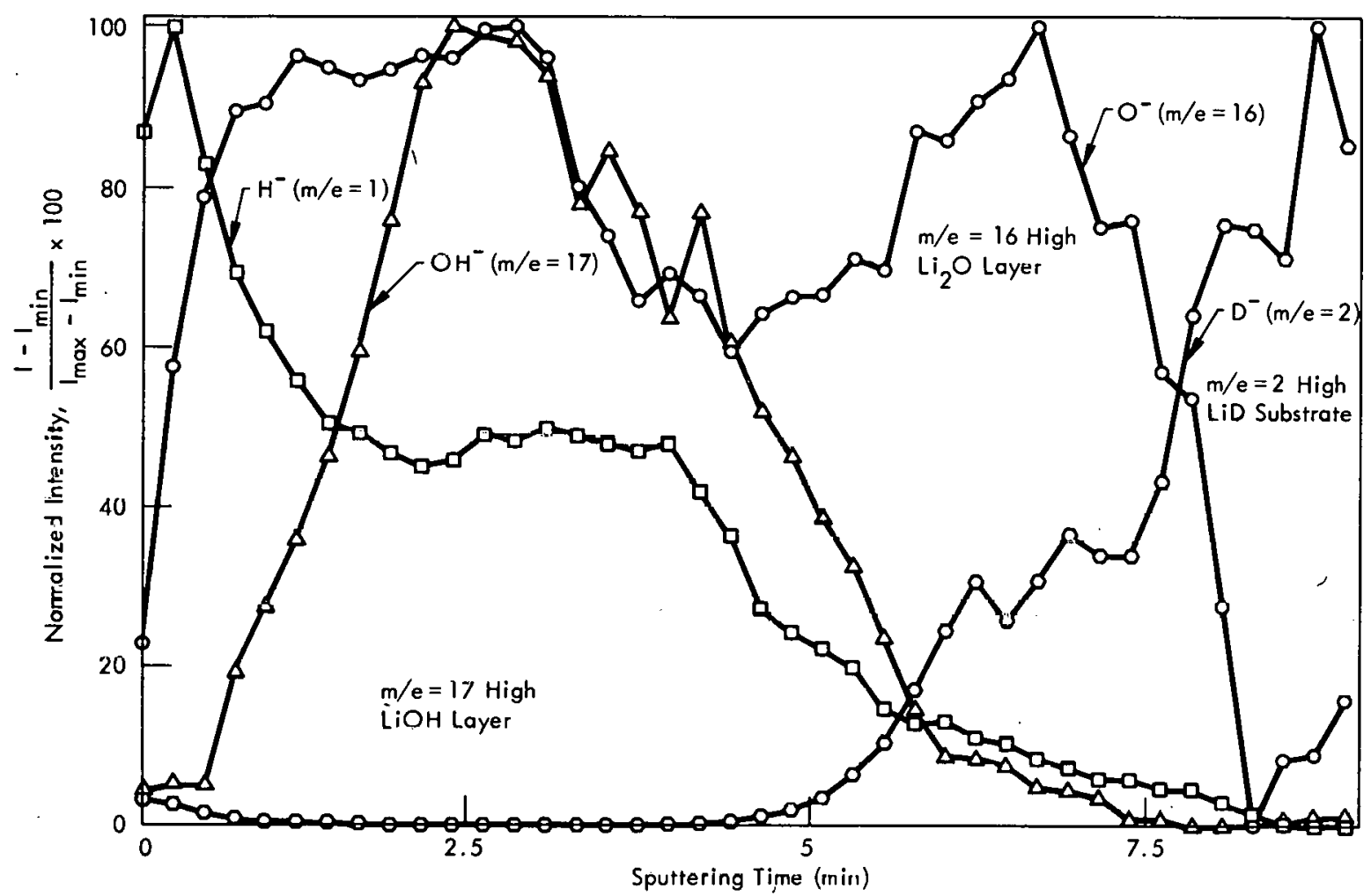

Figure 10. DEPTH PROFILES OF SELECTED MASS NUMBERS AS A FUNCTION OF THE SPUTTERING TIME. (LID Crystal Exposed to $77 \%$ Relative Humidity Air at $72^{\circ} \mathrm{F}$ for 20 Seconds)

Growth rate of the corrosion films on enriched lithium deuteride should be established by timed exposure to carefully controlled humidity conditions. A study of the méchianisin of the growth of the corrosion films, beginning with nucleation and continuing untll the film becomes continuous, is planned. This study will involve both the ron mlcroprobe and high-resolution electron microscopy of replicas of the surface films on the crystal surface.

\section{CONCLUSIONS}

This study has shown that layering does occur in the corrosion of lithium deuteride after exposure to air. The ion microprobe has been used to identify these layers and lo sluw that it exists in the following manner: lithium hydroxide on lithium oxide on lithium deuteride. These data indicate that measurements of the type described in this report are capable of determining the rate of corrosion. 


\section{ACKNOWLEDGEMENTS}

The authors wish to thank the Los Alamos Scientific Laboratory for their financial support for this project and D. S. Catlett of the Los Alamos Scientific Laboratory for his guidance in establishing this program.

Also, gratitude is expressed to H. M. Smith of the Y-12 Ceramics and Plastics Development Department for supplying the enriched lithium deuteride crystals and his many helpful discussions; to C. E. McAlister of the Y-12 Chemistry Development Department for preparing the lithium hydroxide, lithium oxide, and lithium carbonate standards; and to Bertha Mai Melson of the Y-12 Laboratory Development Department for her assistance in the operation of the ion microprobe during the course of this investigation. 


\section{APPENDIX A}

\section{SPECIALLY DESIGNED SAMPLE HOLDER}

Since the preliminary experiments with lithium deuteride showed that it was extremely reactive to moisture, a sample holder had to be developed to protect the lithium deuteride from air exposure. Design of the ion microprobe is such that, in order to load the sample chamber, the chamber is vented to the atmosphere and removed from within the instrument by sliding the chamber out the front of the instrument. This operation is clearly not amenable to containment to provide an inert atmosphere. Some sort of container had to be provided that kept the hygroscopic material from exposure to air during transfer; and, more important, this container had to be opened inside the vacuum system preferably without any modification to the sample chamber.

A view of the vacuum sample holder, designed and fabricated at the $\mathrm{Y}-12$ Plant, is provided in Figure A-1; a drawing of the device is given in Figure A-2; a cross-sectional drawing of the chamber is provided in Figure A-3. This sample holder works in the following manner: A hygroscopic sample is pressed into the cavity in the center of an aluminum sample block; the aluminum sample block is placed in the vacuum chamber of the sample holder; the cap is placed on top of the sample holder; a vacuum line is connected to the pumping port; and the holder is evacuated. The entire operation is performed within an argon-filled glove box with a water content of less than $2 \mathrm{ppm}$.

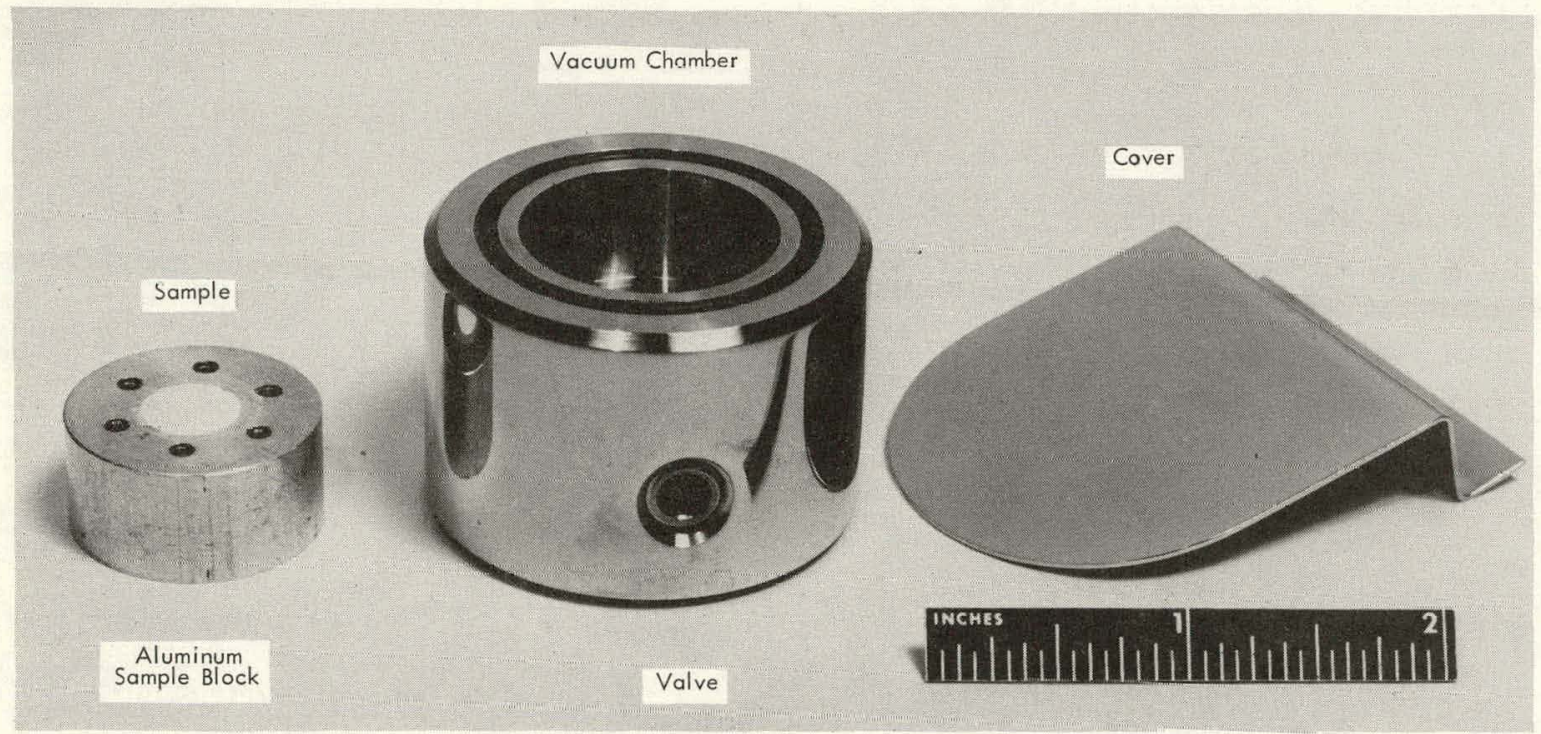

Figure A-1. COMPONENTS OF THE VACUUM SAMPLE HOLDER.

150778

Next, the sample holder is transferred to the sample chamber of the ion microprobe; the cover of the sample holder is secured to the removal fixture (which is mounted inside the sample chamber of the ion microprobe, as seen in Figure A-4); the sample chamber is positioned in the ion microprobe and evacuated. When the pressure inside the ion microprobe equals the pressure inside the vacuum chamber of the sample holder, the cover 


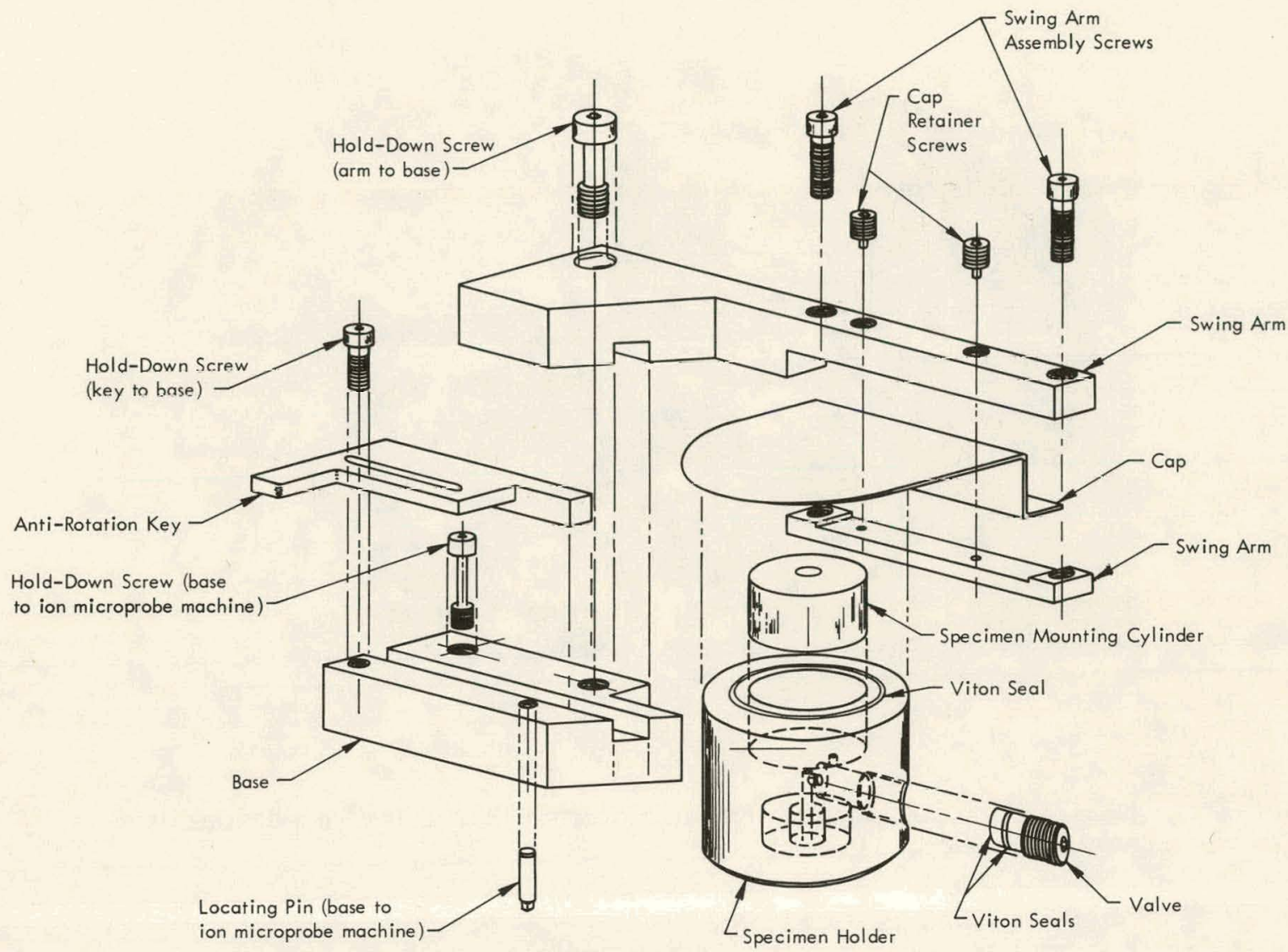

Figure A-2. VACUUM SAMPLE HOLDER AND REMOVER ASSEMBLY.

is freed. The sample holder can then be rotated from under the cover to the position for examination in the ion microprobe, as seen in Figure A-5, without being exposed to air.

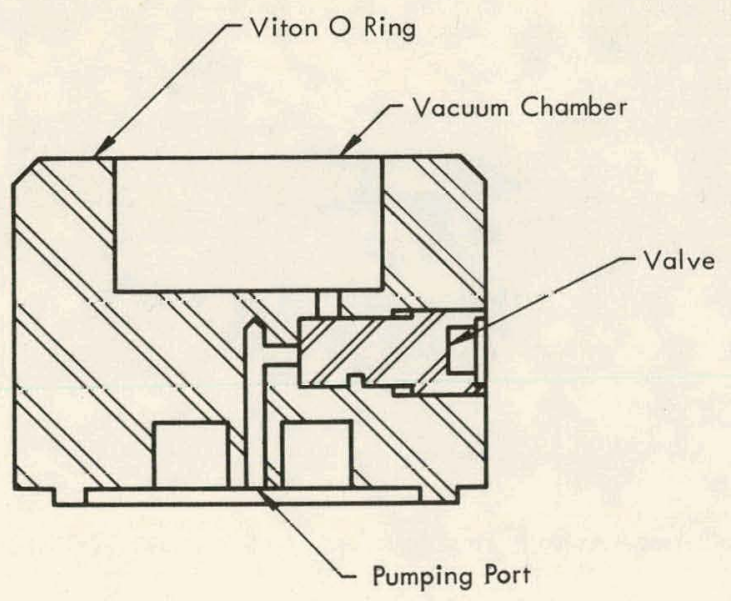

Figure A-3. CROSS SECTION OF THE VACUUM CHAMBER. 


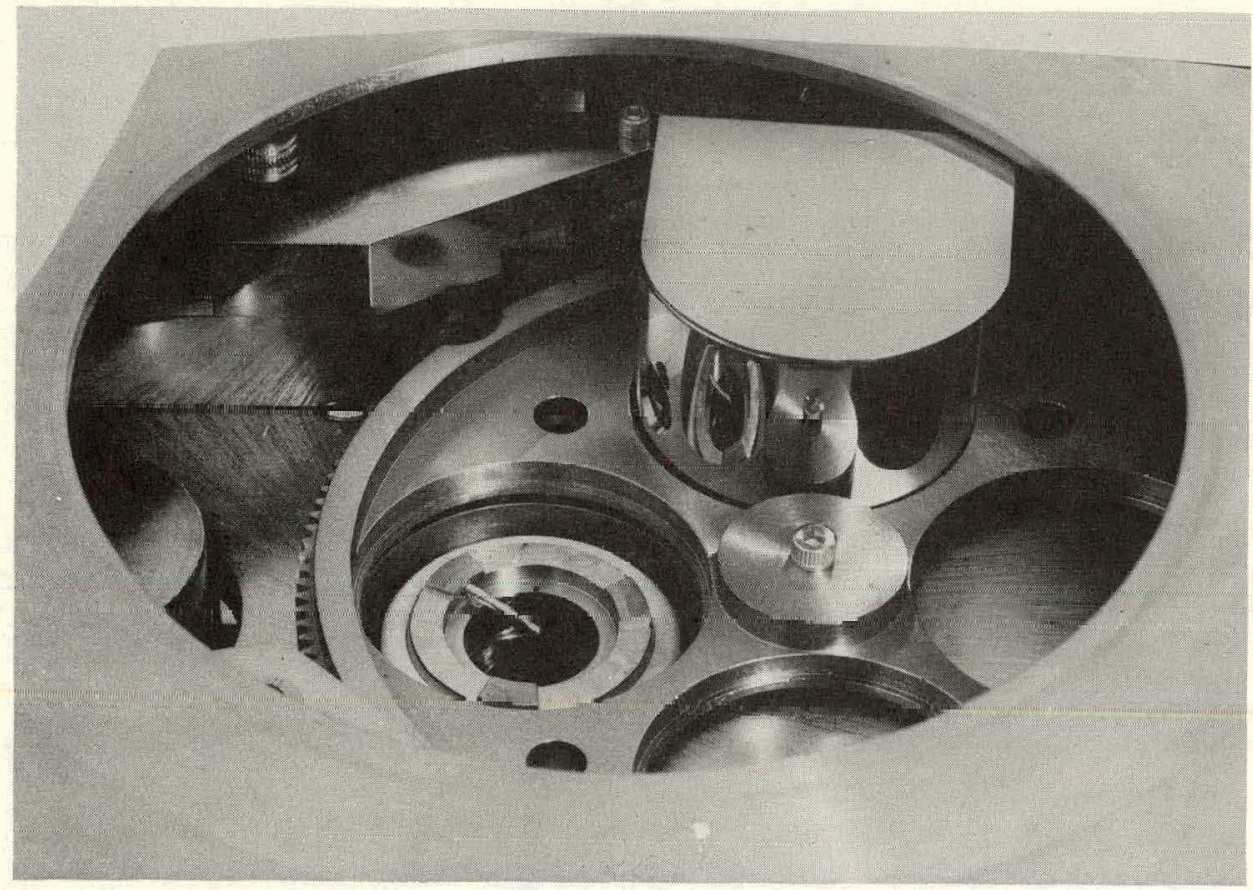

150777

Figure A-4. VACUUM SAMPLE HOLDER MOUNTED IN THE ION MICROPROBE MASS ANALYZER SAMPLE CHAMBER.

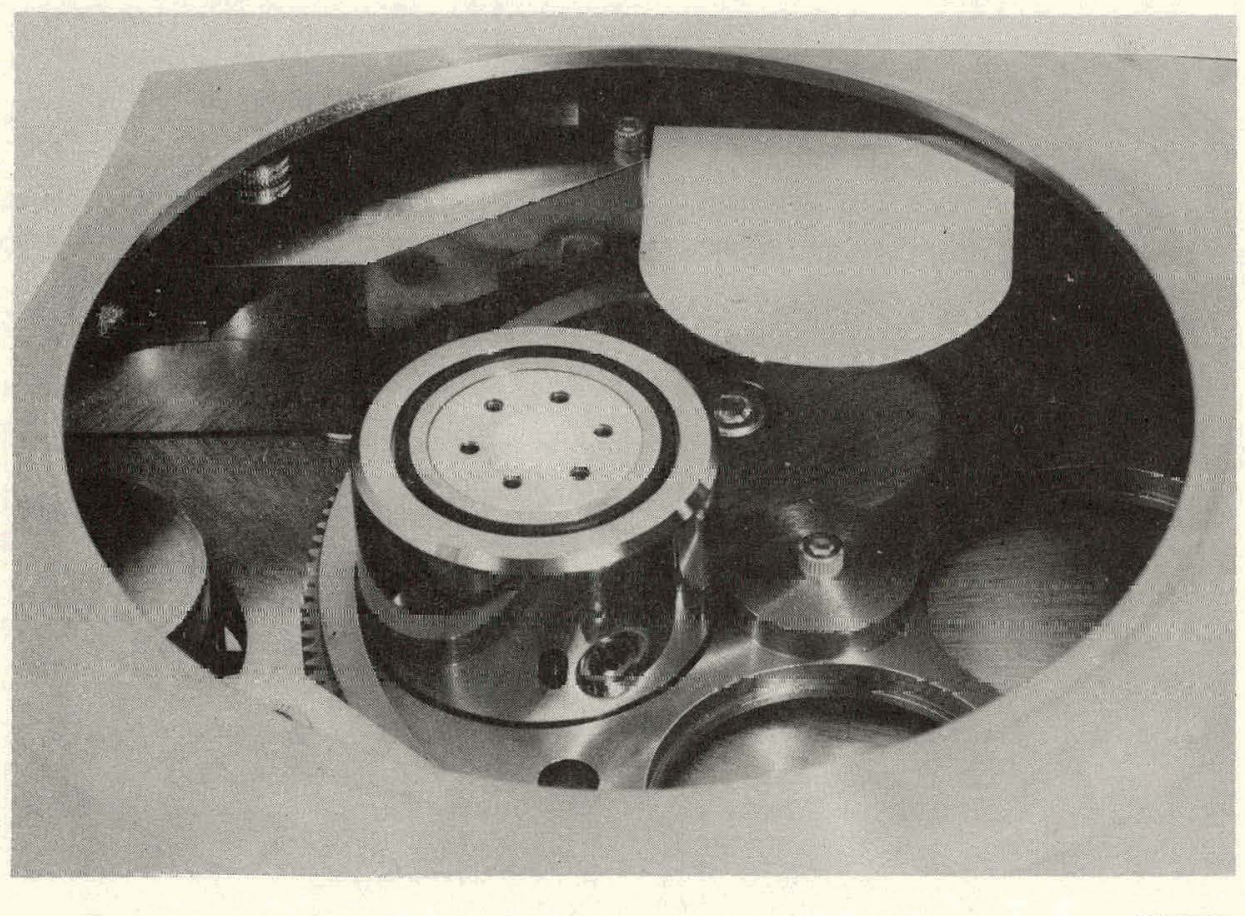

Figure A-5. VACUUM SAMPLE HOLDER ROTATED INTO POSITION FOR SAMPLE INVESTIGATION. 


\section{APPENDIX B}

\section{MASS SPECTRA OF LITHIUM COMPOUNDS}

\section{Introduction}

In the ion microprobe investigation of the corrosion films on lithium deuteride, standard mass spectra had to be obtained for the possible reaction products of the reaction of lithium deuteride with air. These mass spectra of lithium hydroxide, lithium oxide, and lithium carbonate are included in this Appendix so that they may be used as a reference for those readers who may want to use them for identification of corrosion films in ion microprobe mass spectrometry. All of the mass spectra were obtained using a positively charged argon primary beam.

\section{Mass Spectra of Lithium Hydroxide}

The positive mass spectrum for lithium hydroxide powder is given in Figure B-1. Pulsecounting data from this mass spectrum are presented in Table B-1.

The negative mass spectrum for lithium hydroxide powder is shown in Figure B-2. Pulse-counting data from this mass spectrum are reported in Table B-2.

\section{Mass Spectra of Lithium Oxide}

Figure B-3 is a positive mass spectrum of lithium oxide. Pulse-counting data from this mass spectrum are summarized in Table B-3.

The negative mass spectrum of lithium oxide is shown in Figure B-4. Pulse-counting data for this mass spectrum are listed in Table B-4.

\section{Mass Spectra of Lithium Carbonate}

The positive mass spectrum of lithium carbonate is presented in Figure B-5. Pulse-counting data for this mass spectrum are given in Table B-5.

The negative mass spectrum for lithium carbonate is illustrated in Figure B-6. Pulse-counting data for this mass spectrum are listed in Table B-6. 
Table B-1

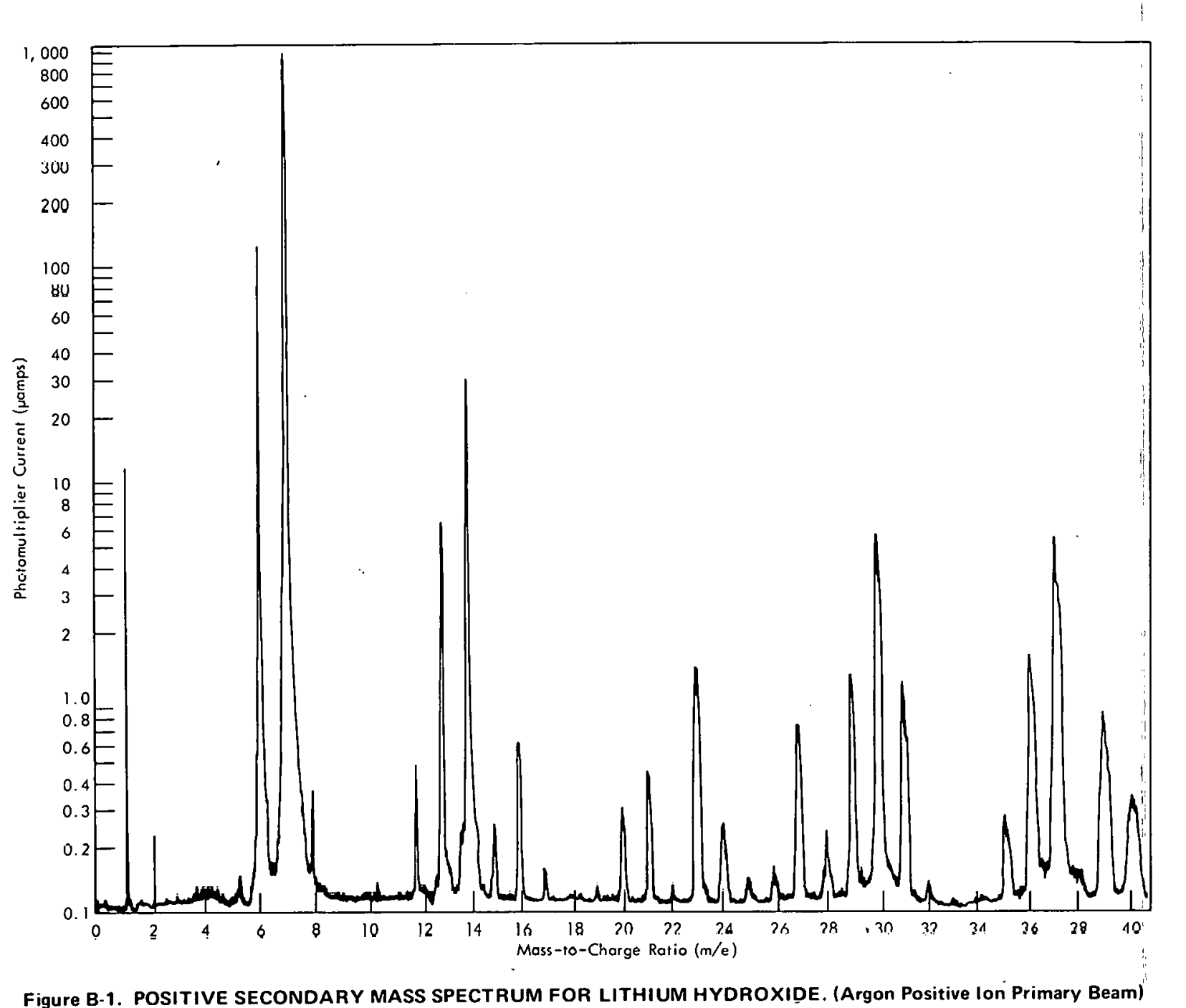

POSITIVE SECONDARY MASS SPECTRUM
FOR LITHUM HYOROXIDE

(Argon Positive lon Primary Beam!

\begin{tabular}{|c|c|c|c|}
\hline Mass & Ion & $\begin{array}{l}\text { Counts (1) } \\
\text { per Second }\end{array}$ & \\
\hline & $\mathrm{H}^{+}$ & 0,163 & \\
\hline 2 & & 61 & \\
\hline $\bar{\sigma}$ & 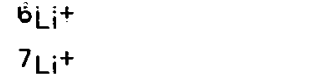 & 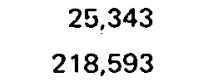 & \\
\hline 12 & ${ }^{6 \mathrm{Li}_{2}^{+}, \mathrm{C}^{+}}$ & 40 & \\
\hline 13 & $\left({ }^{6} \mathrm{Li}^{\mathrm{L}} 77_{\mathrm{Li}}\right)^{+}, \mathrm{CH}^{+}$ & 140 & \\
\hline 14 & ${ }^{7} \mathrm{Li}_{2}{ }^{+}, \mathrm{CH}_{2}{ }^{+} \cdot \mathrm{N}^{+}$ & 531 & \\
\hline 15 & $\mathrm{CH}_{3}{ }^{+}$ & 218 & \\
\hline${ }_{17}^{16}$ & 等+ & 887 & \\
\hline $\begin{array}{l}17 \\
20\end{array}$ & ${ }^{\mathrm{OH}^{+} \mathrm{Li}_{2} \mathrm{G}_{\left.\mathrm{L}_{\mathrm{L}}\right)^{+}}}$ & $\begin{array}{l}44 \\
789\end{array}$ & \\
\hline 21 & $7 \mathrm{Li}^{+}{ }^{+}$ & 1,426 & \\
\hline 23 & ${ }^{\mathrm{LiO}+}+\mathrm{Na}^{+}$ & 7,191 & \\
\hline & $24 \mathrm{Mg}^{+}$ & 869 & \\
\hline 29 & ${ }^{25} \mathrm{Mg}^{\prime}$ & 210 & \\
\hline 26 & ${ }^{26} \mathrm{Mg}^{+}$ & $\begin{array}{r}2.39 \\
4.540\end{array}$ & \\
\hline & $\begin{array}{l}\mathrm{Al}^{2+} \\
{ }^{28} \mathrm{~s}_{\mathrm{s}}+\mathrm{co}\end{array}$ & $\begin{array}{l}4,540 \\
599 \\
59\end{array}$ & \\
\hline 28 & 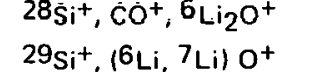 & $\begin{array}{r}6.49 \\
4.257\end{array}$ & \\
\hline 30 & $30 \mathrm{Si}^{+}, 7 \mathrm{Li}_{\mathrm{i} \mathrm{O}^{+}}$ & 23,838 & \\
\hline 31 & ${ }^{p+}, 7 \mathrm{Li}_{2} \mathrm{OH}$ & 5,297 & \\
\hline & $\mathrm{O}_{2}^{+}, 32 \mathrm{~s}^{+}$ & 358 & \\
\hline 34 & ${ }^{34 \mathrm{~S}^{+}, 6 \mathrm{Li}_{3} \mathrm{O}^{+}}$ & 98 & \\
\hline & 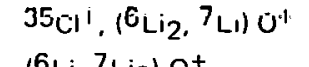 & $\begin{array}{r}3,44 \\
27,60\end{array}$ & \\
\hline 36 & 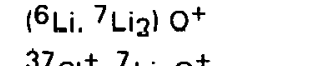 & $\begin{array}{l}27.65 \\
102.10 \\
10210\end{array}$ & \\
\hline & $\begin{array}{l}{ }^{37} \mathrm{Cl}^{+}, 7^{3 \mathrm{Li}_{3} \mathrm{O}^{+}} \\
39 \mathrm{~K}^{+}\end{array}$ & $\begin{array}{l}102,106 \\
7524\end{array}$ & \\
\hline 39 & $\begin{array}{l}39 \mathrm{~K}^{+} \\
{ }^{40} \mathrm{C}^{+}\end{array}$ & $\begin{array}{l}7.524 \\
2.032 \\
\end{array}$ & \\
\hline
\end{tabular}

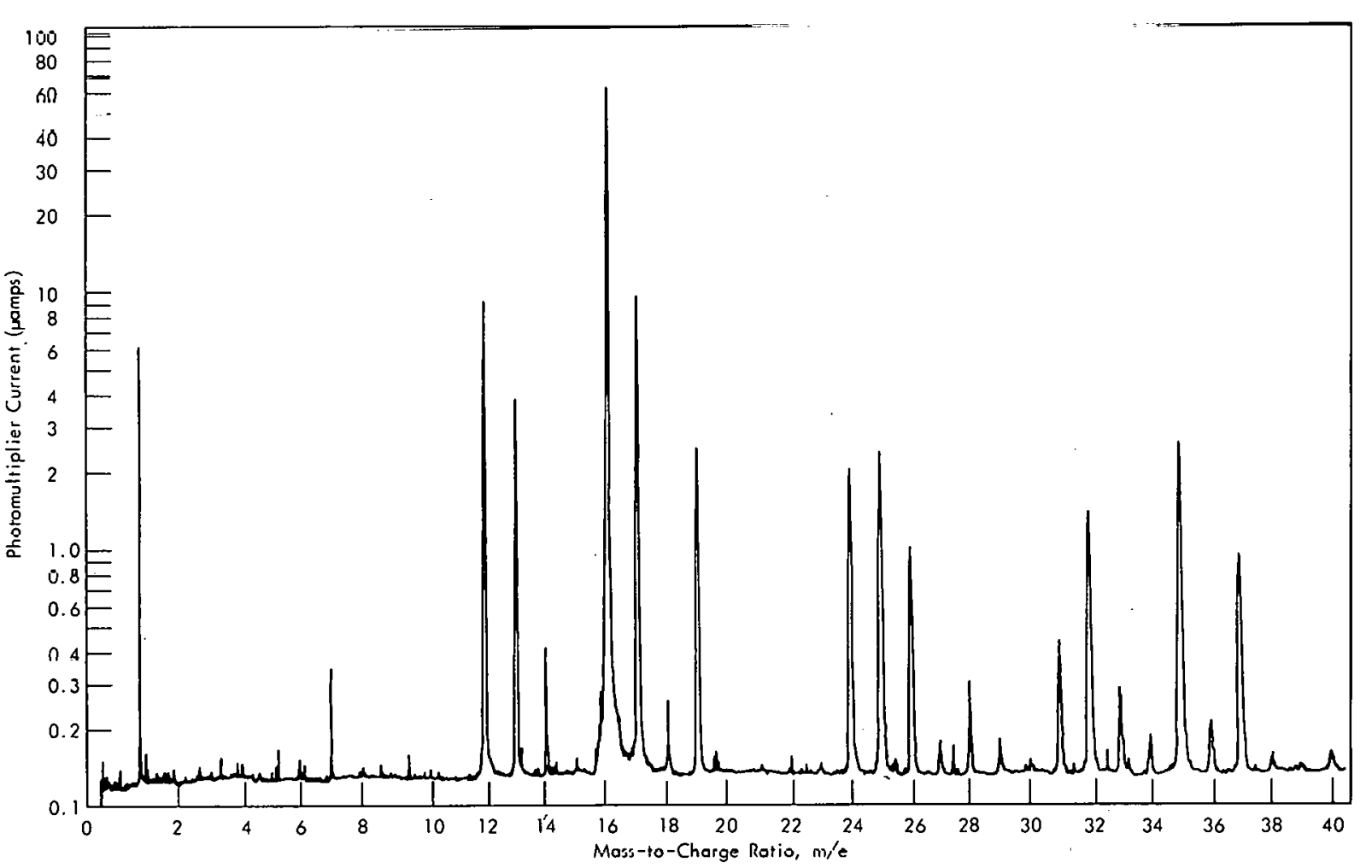

Table B-2

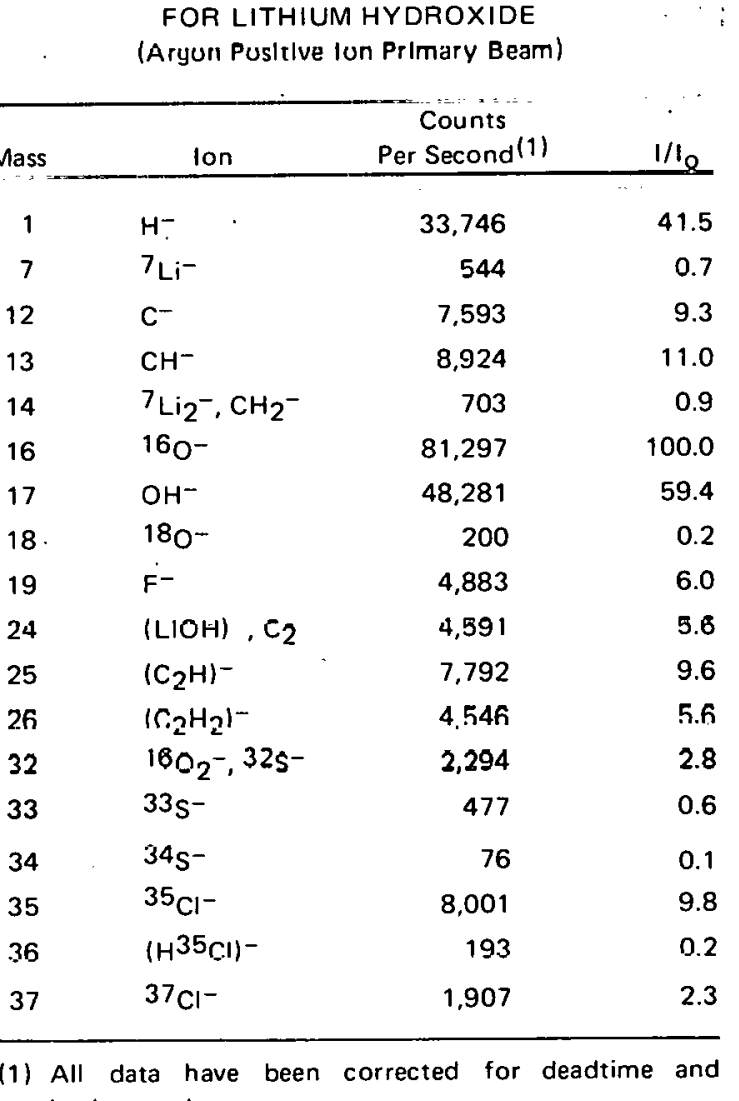


Table B-3

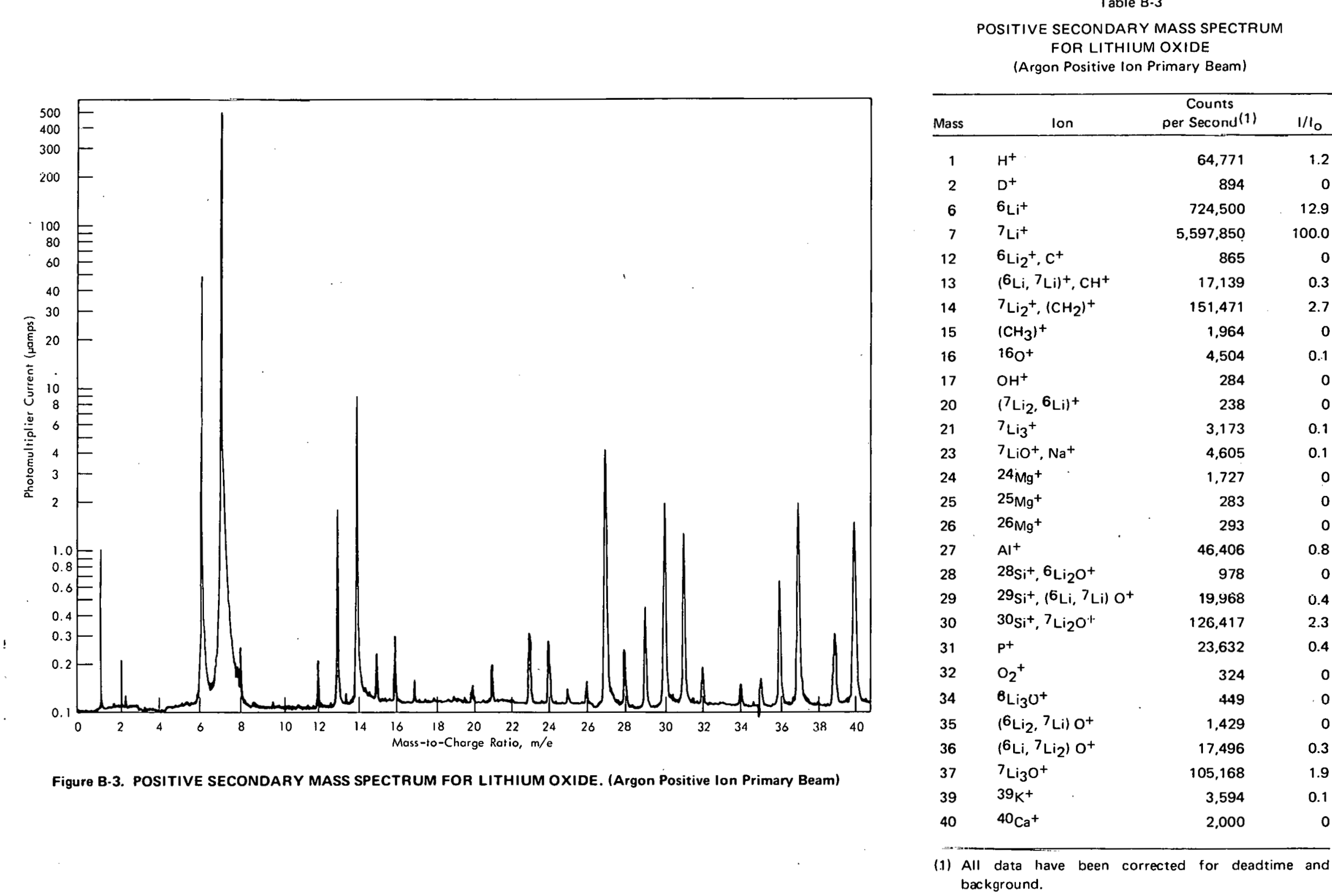

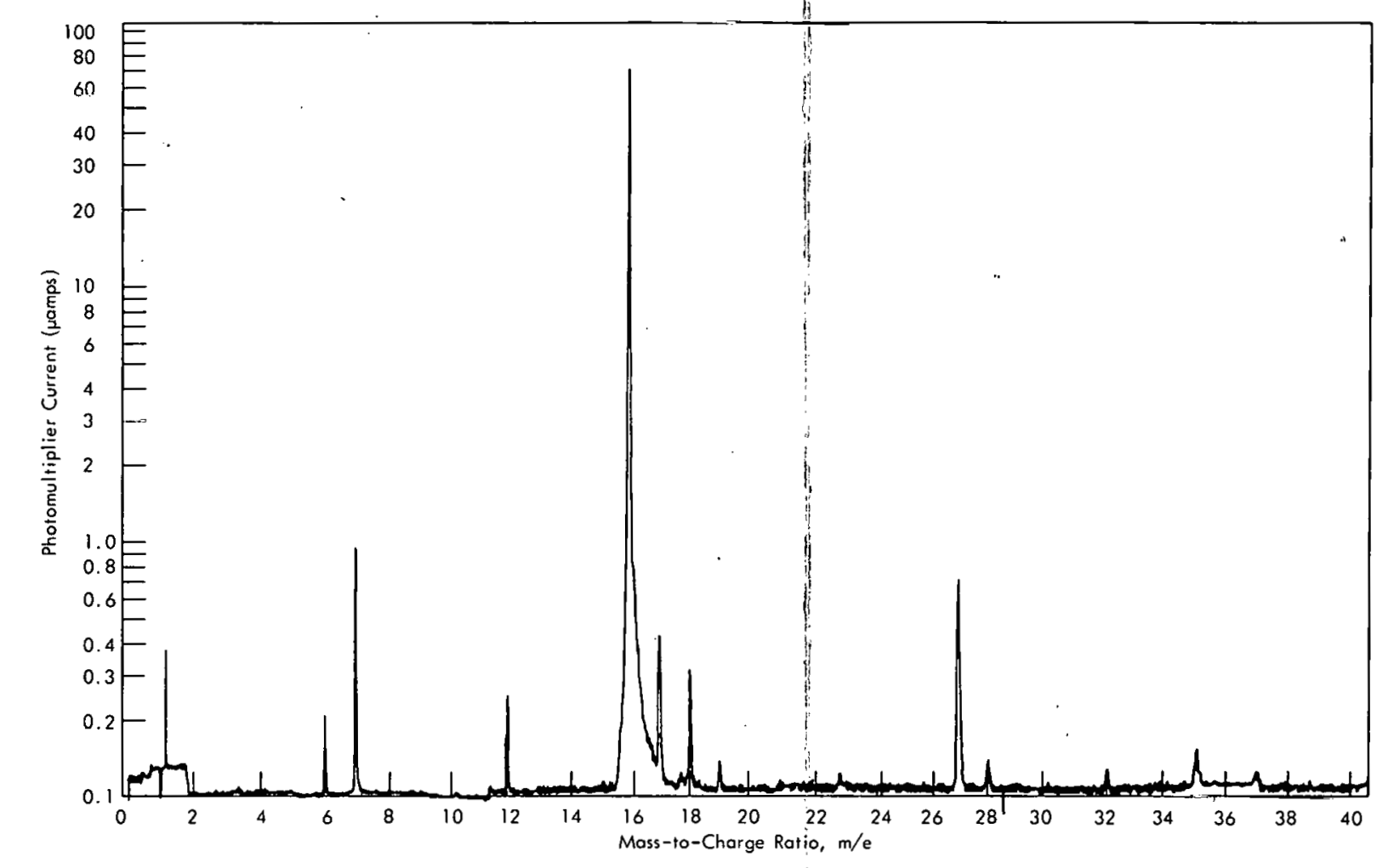

Figure B.4. NEGATIVE SECONDARY MASS SPECTRUM FOR LIThiluM OXIDE, (Argon Positive Inn Primary Ream)
Table 8.4

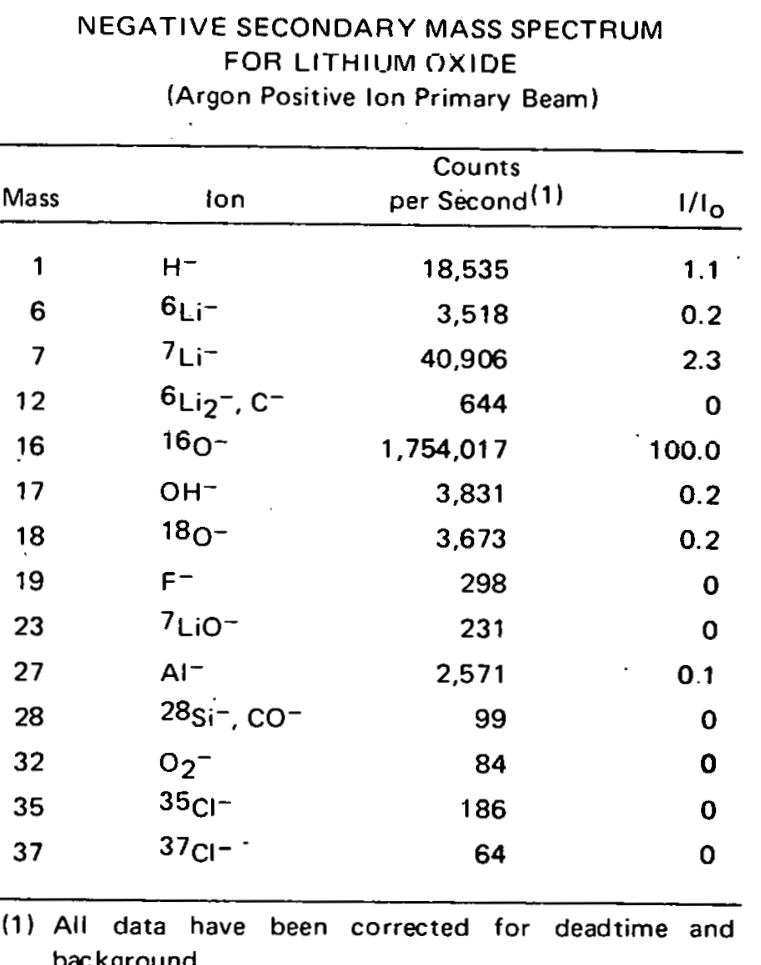




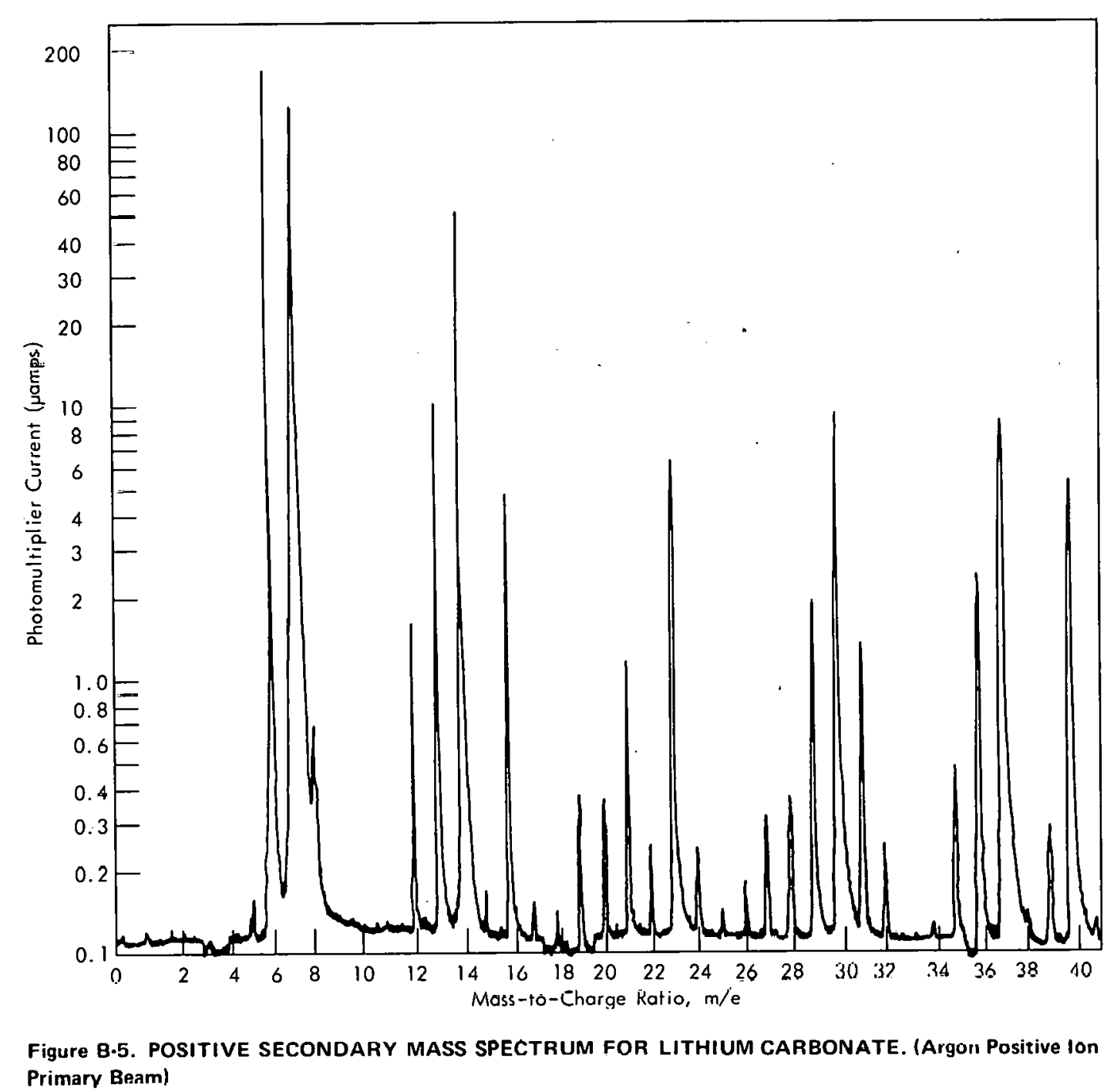

Table B.5

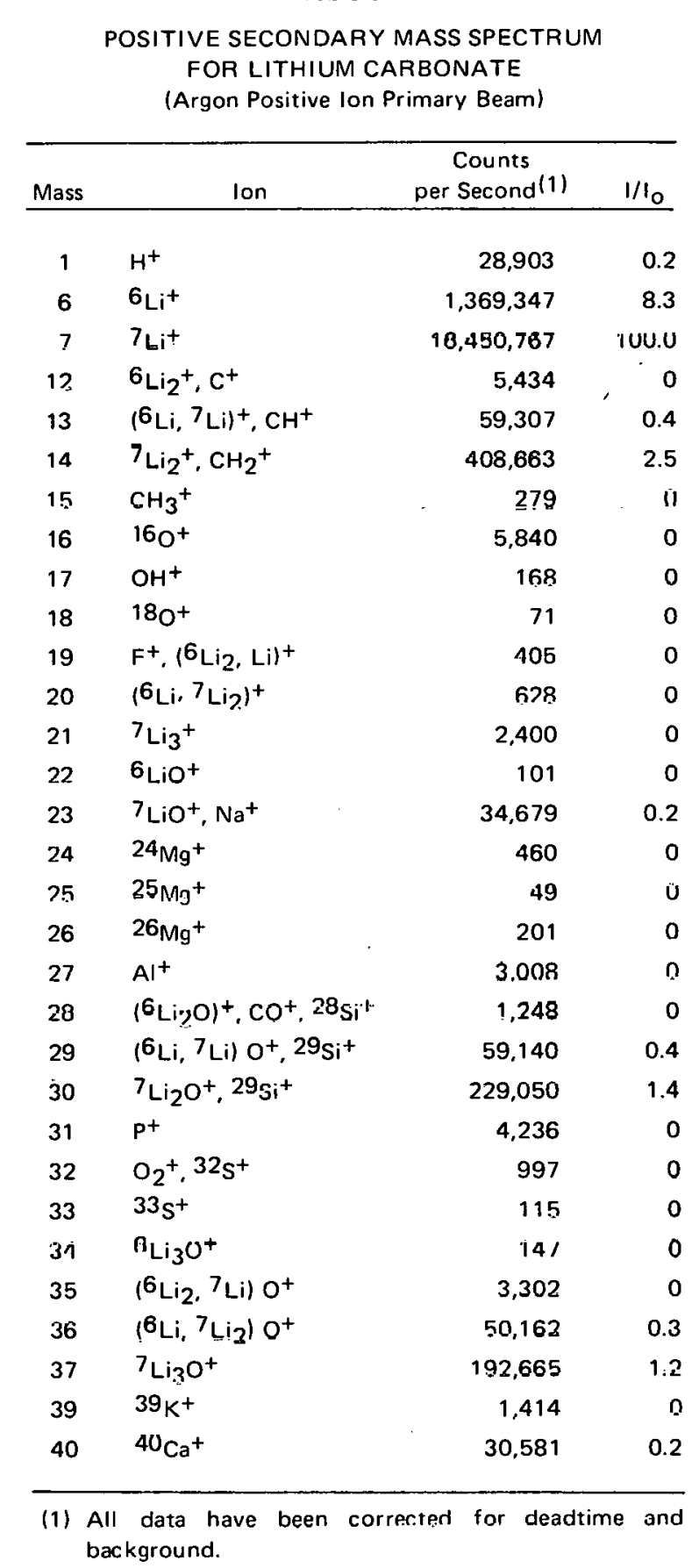

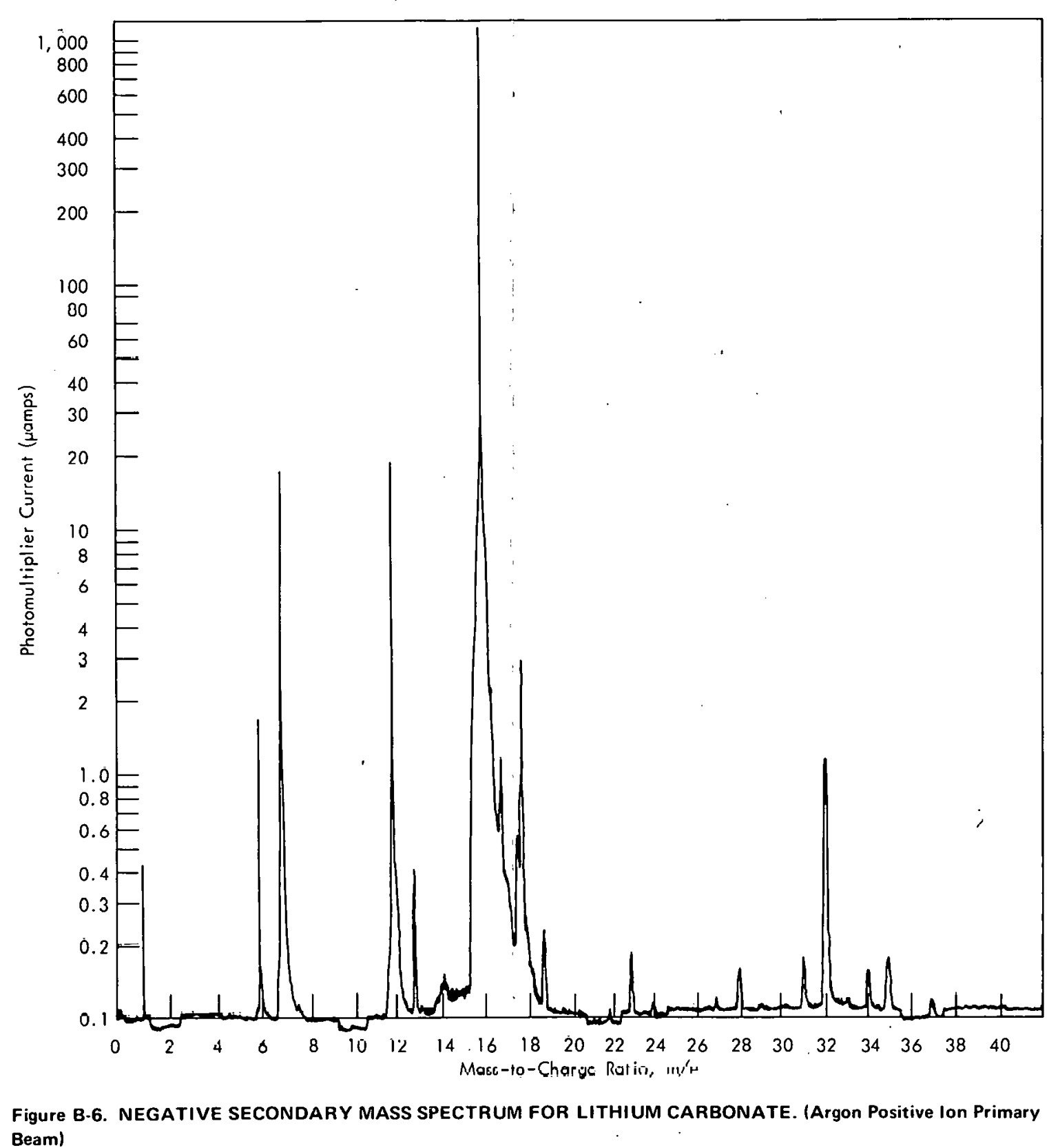

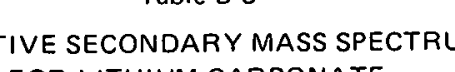

FOR LITHIUM CARBONAT
IArgon Posilive IO Primary B

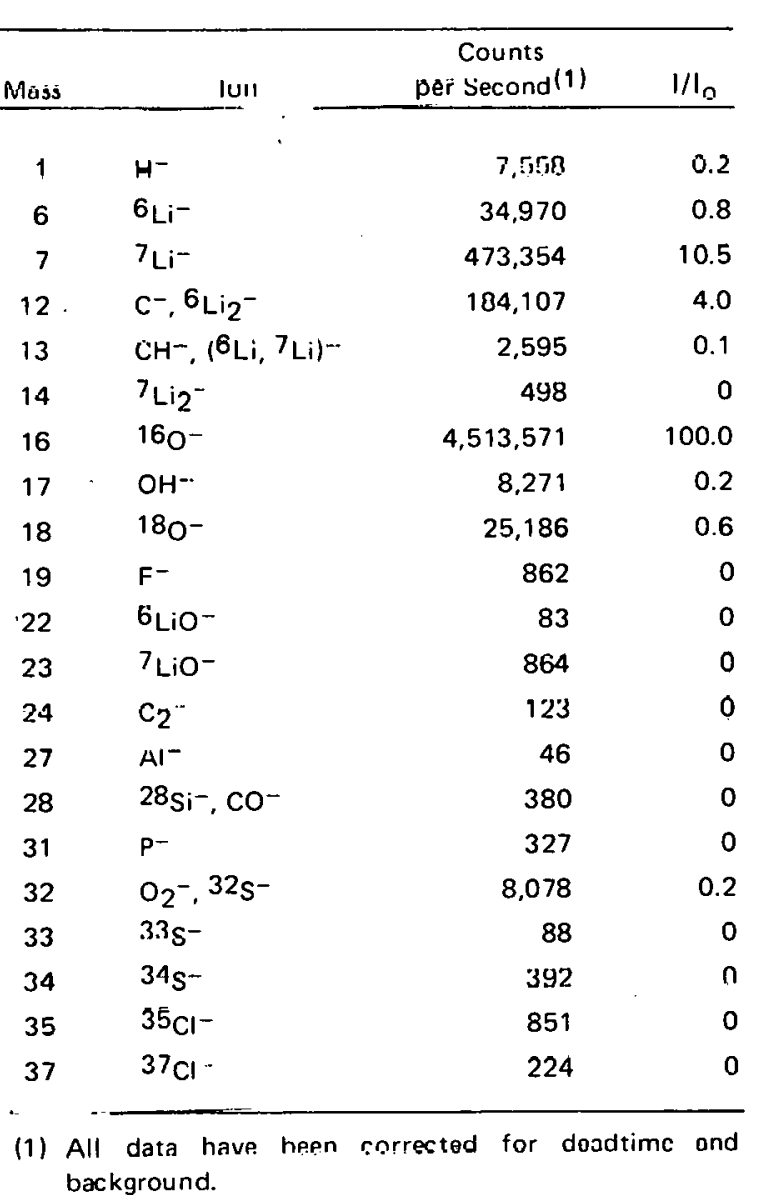

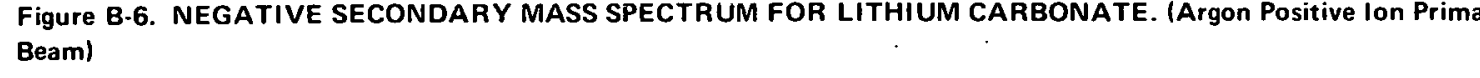




\section{DISTRIBUTION}

Atomic Energy Commission - ORO

Hickman, H. D.

Zachry, D. S., Jr

Lawrence Livermore Laboratory

Colmenares, C. A.

Hickman, R. G.

Leider, $H$.

Weiss, H. D.

Los Alamos Scientific Laboratory

Alire, R. M.

Eyster, E. H.

Plassmann, E. H.

Oak Ridge Gaseous Diffusion Plant

Wilcox, W. J., Jr

Winkel, R. A.

Oak Ridge $\mathrm{Y}-12$ Plant

Bernander, N. K.

Briscoe, O. W.

Burditt, R. B.

Burkhart, L. E.

Cristy, S. S. (5)

Denny, A.

Fultz, C. R.

Jones, F. W.

Kahl, K. G.

Keith, Alvin

Kite, H. T.

Lundin, M. I.

Marrow, G. B.

Mason, D. L.

Mclntyre, J. M.

McLaughlin, J. F. (5)

McLendon, J. D.

Montgomery, C. D.

Phillips, L. R.
Powell, G. L.

Schreyer, J. M.

Smith, H. F., Jr

Smith, H. M.

Smith, R. D.

Tewes, W. E.

Thompson, W. H.

Weathersby, W. E.

Yaggi, W. J.

Y-12 Central Files (5)

Y-12 Central Files (master copy)

$Y-12$ Central Files (route)

$Y-12$ Central Files (Y-12RC)

Paducah Gaseous Diffusion Plant

Levin, R. W.

Sandia - Albuquerque

Guthrie, J. W.

Myers, S. M.

Schwoebel, R. L.

Sandia - Livermore

Aldolphson, D. R.

Tallerico, L. N.

Swisher, J. H.

In addition, this report is distributed in accordance with the category UC-4, Chemistry, as given in the USAEC Standard Distribution Lists for Unclassified Scientific and Technical Reports, TID-4500. 